Running Head: FALSE MEMORIES FOR OBJECT-LOCATION BINDINGS

Out of Place, Out of Mind: Schema-Driven False Memory Effects for ObjectLocation Bindings

\author{
Adina R. Lew* \\ Lancaster University, UK \\ Mark L. Howe \\ City University London, UK
}

*Correspondence concerning this article should be addressed to Adina R. Lew, email:

a.r.lew@lancaster.ac.uk; telephone: +44 (0)1524 593696.

Word count: 12,139 


\begin{abstract}
Events consist of diverse elements, each processed in specialised neocortical networks, with temporal lobe memory systems binding these elements to form coherent event memories. We provide a novel theoretical analysis of an unexplored consequence of the independence of memory systems for elements and their bindings, one that raises the paradoxical prediction that schema-driven false memories can act solely on the binding of event elements despite the superior retrieval of individual elements. This is because if two, or more, schema-relevant elements are bound together in unexpected conjunctions, the unexpected conjunction will increase attention during encoding to both the elements and their bindings, but only the bindings will receive competition with evoked schema-expected bindings. We test our model by examining memory for object-location bindings in recognition (Study 1) and recall (Studies 2 and 3) tasks. After studying schema-relevant objects in unexpected locations (e.g. pan on a stool in a kitchen scene), participants who then viewed these objects in expected locations (e.g. pan on stove) at test were more likely to falsely remember this object-location pairing as correct, compared to participants that viewed a different unexpected object-location pairing (e.g. pan on floor). In recall, participants were more likely to correctly remember individual schemarelevant objects originally viewed in unexpected, as opposed to expected locations, but were then more likely to misplace these items in the original room scene to expected places, relative to control schema-irrelevant objects. Our theoretical analysis and novel paradigm provide a tool for investigating memory distortions acting on binding processes.

Keywords: Schema; False memories; Source memory; Scene memory; Distinctiveness effects; Object-location binding
\end{abstract}




\section{Out of Place, Out of Mind: Schema-driven False Memory Effects for Object-}

\section{Location Bindings}

Witnessed events involve interactions between agents, objects, locations, evoked emotions and actions, all within a temporal context. Current models of memory emphasize this distributed nature of event representations. These individual aspects of events are processed by different brain systems and retained as somewhat independent units, in addition to being bound together to form an episodic memory, a function attributed to the hippocampus within medial temporal lobe memory systems (Hardt, Einarsson, \& Nader, 2010; Horner \& Burgess, 2013, 2014; McClelland, McNaughton, \& O’Reilly, 1995, Rolls \& Treves, 1998).

Another fundamental aspect of remembering events is that they are processed within existing knowledge frameworks, including event schemas, which affect both the interpretation of the event and how attention is allocated (Bartlett, 1932; Graesser, Gordon \& Sawyer, 1979; Graesser, Woll, Kowalski \& Smith, 1980; Schank, 1982, 1999). When accurate memory for witnessed events is required, systematic distortions can occur due to these relations between established knowledge and the event that was experienced. A combination of lower levels of processing of schema-relevant stimuli (Schank, 1982, 1999), activations of neural representations of non-present schema-relevant items due to their associative links within schema knowledge structures during encoding (Gallo, 2010; Johnson, Hashtroudi, \& Lindsay, 1993; Mitchell \& Johnson, 2009), together with expectations that such items would have been present in the to-be-remembered material (Schacter, Israel, \& Racine, 1999), all potentially lead to inaccurate memories. False positives for schema-relevant items can arise due to source confusions for activations (associatively activated as opposed to actually present in the to-be-remembered material), combined with lower 
thresholds for accepting schema-relevant items as having been present. In addition, memory for details of schema-relevant items that were actually present may be poor due to low levels of processing for schema-relevant material (Mäntylä \& Bächman, 1992; Pezdek, Whetstone, Reynolds, Askari, \& Dougherty, 1989).

The converse of these processes occurs when a schema-irrelevant item is observed in that it attracts attention, leading to detailed processing and accurate memory, with the important caveat that the proportion of such schema-irrelevant items in stimuli should remain relatively low (Rojahn \& Pettigrew, 1992). Moreover, metamemorial thresholds for accepting that schema-irrelevant items were present in to-be-remembered material are high, leading to low levels of false memories (Lampinen, Copeland, \& Neuschatz, 1991; Mäntylä \& Bächman, 1992; Pezdek et al., 1989; Schacter et al., 1999). Thus, we are unlikely to remember the exact phrases used by a waiter asking us what we want to eat in a restaurant (schema-relevant) but much more likely to remember the details of the words used if the waiter asked us instead what our favourite color was (schema-irrelevant). It is also very unlikely that we would falsely remember that we were asked what our favorite color was, whereas we may falsely remember we were asked what we wanted for dessert. The term distinctiveness effects will be used as a summary term to refer to these attentional and metamemorial processes making schema-irrelevant items more memorable and less prone to false recollection and schema-relevant items more prone to false recollection. An interesting aspect of the large literature investigating systematic memory distortions due to schemas has been a focus on memory for individual elements of a person description, narrative, scene or event, rather than how constituent elements are bound together, a gap we address in the present research using a novel paradigm. Consonant with distinctiveness effects, the findings across the domains of social 
stereotypes (Rojahn \& Pettigrew, 1992; Stangor \& McMillan, 1992), narratives (Bower, Black, \& Turner, 1979; Graesser et al., 1979, 1980; Lampinen, Faries, Neuschatz, \& Toglia, 2000, Nakamura \& Graesser, 1985), room scenes (Brewer \& Treyens, 1981; Lampinen et al., 2001; Mäntylä \& Bächman, 1992; Pezdek et al., 1989), filmed events (Aizpurua, Garcia-Bajos, \& Migueles, 2009; Garcia-Bajos \& Migueles, 2003; Migueles \& García-Bajos, 1999; Neuschatz, Lampinen, Preston, Hawkins, \& Toglia, 2002; Tuckey \& Brewer, 2003; Yamada \& Itsukushima, 2013a, 2013b) and real events (Nakamura, Graesser, Zimmerman, \& Riha, 1985) has been that although true memory performance for schema-relevant elements is high, false memories for schema-relevant foils or intrusions are also high. In contrast, schemairrelevant items show high levels of true memory combined with low levels of false memory, as long as the proportion of schema-irrelevant items is not too great, potentially attenuating schema evocation (Rojahn \& Pettigrew, 1992).

When the focus of research attention is on the binding between elements, a hitherto unexplored consequence of the independence of memory for individual elements relative to binding of those elements (Horner \& Burgess, 2013, 2014; McClelland et al., 1995, Rolls \& Treves, 1998) could be that schema-driven false memory effects act solely on the binding between elements, as we elaborate below. In forensic contexts witnesses are not only required to recall individual aspects of an event, such as whether a particular person was present, but also where the person was, what they were doing, and with what objects (Howe \& Knott, 2015). Whether threatening language was used by a slight or burly individual in a group during a witnessed altercation, or whether a kitchen knife was seen on the floor, table or in its usual holder prior to a crime could be important within a legal context. Thus, it is of 
practical as well as scientific interest to understand how schemas can affect accuracy of memory for the binding between elements.

If the focus of interest is to isolate schematic distortion effects acting on the binding between elements, it is necessary to consider a situation where all the individual elements of that situation are schema-relevant and only the linkage between two or more elements is schema-unexpected. An example can be observed in the top panel of Figure 1 where a teapot is placed on a stool in a kitchen scene. In our proposed model, the unexpected linkage attracts attention (as predicted by distinctiveness effects) but also associatively evokes schematically-expected bindings (teapot on work-surface and perhaps person on stool). The counterintuitive prediction that emerges from these processes is that memory for the individual elements will be enhanced (e.g., the teapot and stool), because of the attention they received, as well as because of the evocation of the schematically-expected bindings that will necessarily involve the individual elements. However, memory for the unexpected binding may be impaired, due to competition from the evoked schematically-expected bindings (e.g., teapot on stool versus teapot on work-surface). A source memory error may occur because a strong but implausible memory trace is competing with a weaker, associatively evoked, but more plausible memory trace. This prediction differs from the traditional view of distinctiveness effects, whereby both memory for the distinctive item and contextual detail should be enhanced, as no distinction is made between individual elements and their bindings (Lampinen et al., 2001; Schank, 1982, 1999).

In order to test for schema-driven effects acting specifically on the binding between elements, it is necessary to present target stimuli with schema-unexpected bindings at study and then in one test situation, present the schema-expected binding 
while in another to present a different schema-unexpected binding. Any difference in performance in terms of judging whether the binding between elements was present in the original material can be ascribed to schema-driven distortions. Whether the difference can be accounted for by the competition we suggest is occurring between actual and evoked bindings between elements and/or by guessing biases towards endorsing schema-expected bindings as correct is an issue that is addressed in depth in our series of studies.

We decided to operationalize the paradigm suggested by the analysis presented above using object-location bindings within schematic scenes. This is because the brain systems underlying independent object and location memory, as well as object-location bindings, are well defined (see reviews in Byrne, Becker, \& Burgess, 2007; Knierim, Lee \& Hargreaves, 2006; Lew, 2011; Postma, Kessels, \& van Asselen, 2008; Torralba, Oliva, Castelhano, \& Henderson, 2006). The effectiveness of schematic rooms with respect to schema-driven distortions on object memory within the rooms has been robustly demonstrated (Brewer \& Teyens, 1981; Friedman, 1979; Lampinen, et al., 2001; Mäntylä \& Bächman, 1992; Pezdek et al., 1989). With regard to placement of items in schema-evoking scenes, studies by Mandler and Parker (1976) and Hess and Slaughter (1990), in which participants had to remember the spatial arrangement of items in a schematically logical or scrambled scene (e.g., of a kitchen), showed that errors tend to occur in the direction of schemaexpected object placements, thus indicating schema-driven distortions for placement of items. In visual search paradigms, schematic scene knowledge guides visual attention during search for target items within scenes e.g. directing vision to floor areas when searching for shoes (Hollingworth, 2009; Torralba et al., 2006). 
Pezdek et al. (1989; also Mäntylä \& Bächman, 1992) and Lampinen et al. (2001) studied memory for objects in a room (graduate student office) in relation to schema relevance. The room contained items that were schema-relevant (office items) as well as those that were schema-irrelevant (toys). On tests of recall and recognition, participants showed more false memories for schema-relevant than schema-irrelevant items that had not been present at study, as well as exhibiting high levels of true memories for schema-irrelevant items. Lampinen et al. (2001) found that memories for schema-relevant items, whether true or false, attracted more "know" as opposed to "remember" responses from participants, where a "know" response indicates a sense of familiarity but without distinctive details, thus indicating that high true memory performance for schema-relevant items does not necessarily reflect strong memory traces.

In the current research, we use photographs of schema-evoking rooms (bathroom, kitchen, living room, and office) that contain target objects that belong within the schema, as well as many other additional schema-relevant objects and features. The target schema-relevant objects are present either at expected or unexpected locations. Target schema-irrelevant objects are also present, that is objects that do not belong within the schema for the room scene (e.g., a doll in the kitchen scene, Figure 1 top panel). After study of the scene, and following a distractor task, a test scene is shown where target objects have either remained in place or have shifted location. Additionally, schema-relevant foil objects not present at study are added, either at schema-expected or schema-unexpected locations, together with further schema-irrelevant objects. Participants have to indicate whether they think a target object was present in the place shown when originally presented. Two between-subjects conditions were used, with the only difference between 
conditions being that in one condition, a target schema-relevant object originally in an unexpected location, e.g., teapot on a stool in the kitchen scene, is shifted to an expected location at test, e.g., teapot on the work-surface, whereas in another condition it is shifted to a different unexpected location, e.g., teapot on foot-shelf of table (Figure 1).

The critical prediction we make following our analysis of schema-driven false memory effects targeted on the binding between elements is that performance will be reliably lower (more false memories) for objects shifted from unexpected to expected locations compared to objects shifted from unexpected to different, but still unexpected, locations. Note that this prediction is different to that arising from distinctiveness effects as traditionally formulated which do not take into account the potential separation between elements and their bindings. The traditional prediction would be that the initial unexpected location for the object would lead to high levels of true memory for the original location in both conditions, due to the distinctive object-location combination being attended to.

It is important to demonstrate that having an object that belongs to a schematic scene in an unexpected location does indeed give rise to distinctiveness effects in terms of memory for that object, as this has yet to be demonstrated within the scene memory paradigm. We thus predict that for non-shifted objects, the characteristic pattern of high true memories and low false memories for schema-irrelevant objects that has been obtained in most prior research (Lampinen et al., 2001; Mäntylä \& Bächman, 1992; Pezdek et al.; 1989) will also occur in our study, and the same pattern of effects will occur for the schema-relevant objects in unexpected locations. Conversely, high levels of true memories combined with high levels of false 
memories are predicted for schema-relevant objects in expected locations.

\section{Study 1}

\section{Method}

\section{Participants.}

Participants were first year psychology students gaining partial course credit for research participation. There were 20 participants in the shift-to-expected condition (19 females, mean age $=19.2$ years, range $18-29$ years $)$ and 20 in the shiftto-unexpected condition ( 16 females, mean age $=20$ years, range $18-40$ years). Because this is a novel paradigm, we based our sample size on prior piloting for the between-subjects comparison. For the within-subjects factors, a sample size of 40 is comparable to the samples used in prior research (Lampinen et al., 2001; Pezdek et al., 1989). The study was approved by the University Ethics Committee and conformed to British Psychological Society and American Psychological Association ethical guidelines.

\section{Stimuli.}

The main stimuli used in the experiment were color digital photographs of 4 different room environments: bathroom, kitchen, living room, and office (each photograph was standardized to $1300 \times 864$ pixels). Associated with each room were 12 target objects (see Table 1). There were 12 possible versions of each photograph of each room, only one of which was viewed by each participant during initial study of each room photograph. Each version of each photograph used for initial study by participants had 2 possible associated test photographs. Figure S1 shows the exact scheme used to create the different versions of each room photograph, and the rationale for the different versions is explained in the Design section below. 
In order to familiarize participants to the requirements of the task, a single photograph of a $5^{\text {th }}$ environment, a seminar room, was used. An associated test photograph of this study image was constructed in which one of two target objects remained in place, the second object was moved, and a new target object was also added to this test image. Target objects were circled. The practice images were laminated, together with a laminated printed sheet containing the test question in large bold font i.e., "was this object in this place before". This question remained next to the computer used to present the stimuli in the actual study so that participants did not have to remember the test question while responding in test phases. Other than the practice materials that were printed and laminated, the study was conducted using PsyScript (Slavin, 2003-14) running on a 15.4 inch MacBook Pro laptop. The stimuli and script are available on request from the authors.

Two normative studies were conducted to check both the schema relevance of the target objects selected for each room scene and the expectedness of object placements within the scenes. In the first study, 12 participants who were university undergraduates or postgraduates ( 5 females, mean age 22.3 years, range 18-27 years) rated the schema-relevance of each of the 12 objects associated with each of the 4 rooms on a scale of 1 (very usual) to 10 (very unusual). The objects were photographed individually in canonical orientations with background removed using GIMP (free picture editing software, http://www.gimp.org). The means and SDs of the ratings for each object are displayed in Table 1 . The mean typicality ratings for all schema-expected objects were below 3 and all typicality ratings for schemairrelevant objects were above 5, the only exceptions being the doll and bed pillow for the living room, and the kettle for the office. For the bed pillow, the cause of the ratings may have been the confusability of the image with a cushion, which was not 
an issue when the object was seen in the living room context and relative size could be gauged. The effect of having these few objects with low atypicality ratings may be to weaken differences between types of objects, thus leading to more conservative effects.

In the second normative study, 12 undergraduate and postgraduate participants (9 females, mean age 20.5yrs, range 18-26 years) rated the expectedness of the location of the schema-consistent objects on a scale of 1 (very usual) to 10 (very unusual). The means and SDs of these ratings are also presented in Table 1. All means for the schema-expected locations were between 1-3 and all means for the unexpected locations were above 5, the only exceptions being the paper lamp on the mantel-piece in the living-room scene and the desk-chair at the table in the office scene. The ratings for these 2 object-location pairings were still higher in terms of being considered more unusual than the ratings for the schema-expected locations however.

\section{Design.}

Figure 2 illustrates the design of Study 1 in terms of types of objects (schema relevant or irrelevant) present in each of 4 scenes (bathroom, kitchen, living room, office), whether they were target objects present during study, or foils only present during a recognition test, whether the target objects were studied in expected, unexpected or irrelevant locations, and whether the target objects shifted or remained in place between study and test. A mixed design was employed. The between-subjects factor was that of condition, whereby in the shift-to-expected condition one schemaconsistent object in each room that was initially in an unexpected location was shifted to an expected location. In the shift-to-unexpected condition, the same object was shifted to a different unexpected location. It was necessary to make this a between- 
subjects factor so that the same objects within the same contexts could be compared purely in terms of where they were moved to in test photographs, something which would not be possible in a fully within-subjects design.

Within-subject independent variables were the initial location of objects (schema-expected, unexpected, or irrelevant for schema-irrelevant objects) and whether the objects were present at study or not. Two different dependent variables were analyzed. The first research question concerned whether levels of true and false memories for non-shifted objects would vary as a function of location, in order to ascertain whether a schema-relevant object in an unexpected location shows similar distinctiveness effects to those obtained in prior research for schema-irrelevant objects (Lampinen et al., 2001; Pezdek et al., 1989). The proportion of Yes responses to the question, "was this object in this place before", was used as the dependent variable and only the non-shifted objects were used in the analysis. Proportions were used for the total number of schema-relevant objects that were in expected locations across the 4 rooms, calculated out of a total possible 4 . This was the same for the total number of schema-relevant objects in unexpected locations and the total number of schemarelevant objects only present in test images, either at expected or unexpected locations. However, there were 8 schema-irrelevant objects in total ( 2 per room) that did not shift between test and study images. There were 9 schema-irrelevant objects ( 3 per room) that were not present at study but were present in test images. The reason for this imbalance was so that we could have equal numbers of schema-relevant and schema-irrelevant target objects per room as in previous research (Lampinen et al., 2001; Pezdek et al., 1989). A 2(Condition) x 3(Location) x 2(Present at Study) mixed analysis of variance (ANOVA) on the dependent variable proportion of Yes responses 
(correct response for objects present at study, and incorrect for foils) was conducted to investigate true and false memories as a function of object type and location.

The second dependent variable was the proportion of correct responses to the question, "was this object in this place before", where only shifted objects were analyzed. Note that the correct response was always "no". To address the question of whether there was a difference across conditions in the proportion of correct responses to shifts in schema-relevant objects originally in unexpected locations, a 2(Condition) $\mathrm{x}$ 3(Location) mixed ANOVA was performed on the proportion of correct responses for shifted objects.

For all analyses, tests of significance were 2-tailed, and a $p$-value of $<.05$ was used to reject the null hypothesis. The Greenhouse-Geisser correction for unequal variances was applied where relevant in all analyses.

As outlined in the Stimuli section, 12 different versions of each of the 4 room scenes were constructed to counterbalance which irrelevant objects were present (either those numbered 7.-9. or 10.-12. in Table 1), which unexpected locations were used (list 1 or 2 in Table 1), and which of the schema-relevant objects took the role of being in expected, unexpected or not present locations ( 2 objects in each of these roles in each photograph). Additionally, in order to counterbalance which of the 2 schemarelevant objects in each role remained in place (one version) or shifted (the second version; shifting from list 1 to list 2 locations or vice versa), each study version of the scene was paired with one of 2 test photographs. Finally, in test photographs, which irrelevant object shifted out of the possible 3 was counterbalanced, as well as which schema-relevant foil was located in an expected or unexpected location in the test photograph (see Figure S1 for exact scheme used to derive different scene versions). 
The top panel of Figure 1 displays version 2 (see Figure S1) of the kitchen, with one of the two associated test photographs shown in the middle panel. In this example schema-relevant target objects in expected places at study are the pan and toaster, those in unexpected places are microwave and teapot, and those not present are fruit-bowl and kitchen roll. The walking boots, bath towel and doll serve as the irrelevant target objects. In the test image, the toaster shifts from the work-surface to an unexpected location on the floor, the teapot shifts from the stool to an expected place on the work-surface and the bath towel shifts from the table rail to the back of the stool. The kitchen roll is added as a foil in an expected location (work-surface to the right of the sink), and the fruit-bowl is added as a foil in an unexpected location (foot-shelf of table). Three further irrelevant objects are also added as foils (pile of books, umbrella and hat). The only difference between test photographs in each condition was in the single schema-relevant object in each room initially seen in an unexpected location that then shifted to an expected location (shift-to-expected condition) or shifted to a different unexpected location (shift-to-unexpected) in the test photograph (Figure S1). In the example in Figure 2, the teapot would shift to the foot-shelf of table instead of the work surface in the shift-to-unexpected condition, with all other target objects and foils being the same between conditions.

\section{Procedure.}

The task consisted of a study phase, followed by a distractor task, followed by a recognition memory test. Participants were instructed that they would be presented with 4 scenes for 12 seconds each and then be tested on their memory for that scene. Following a 30s distractor task after the presentation of one of the scenes, participants were presented with a test scene, where objects would be highlighted in turn, and they would be required to press either the Y key for "Yes" or the N key for "No" in answer 
to the memory question, "was this object in this place before". During training, it was made clear that a "no" answer could be based on lack of memory for the object itself or a judgement that the object had been present but in a different location. When participants were ready, they could press the return key to advance to the next scene. The process was rehearsed using the laminated and printed training image of a seminar room in which a potted plant, desk, exercise machine, and kettle were used as target objects, each of which was circled in a test image. The task lasted approximately 10 minutes in total. The distractor task was a reaction time task in which participants had to press any key in response to a target animal appearing on the screen (e.g., cat) amidst distractor animals (e.g., hippopotamus, giraffe, and frog). During presentation of test scenes, there was a $0.5 \mathrm{~s}$ interval between the participant pressing the $\mathrm{Y}$ or $\mathrm{N}$ key and the next object being highlighted. Responses ( $\mathrm{Y}$ or $\mathrm{N}$ key-presses) to the relevant image and circled target objects were recorded automatically as part of the PsyScript program.

The order in which the four room scenes were presented was pseudorandomized so that each room appeared once only. There was random selection for each participant as to which version of the study scene was presented, followed by random selection of which associated test scene was presented (see Table 1 and Figure S1). The order in which each of the 12 objects in each test scene was highlighted for participants to respond to was also pseudo-randomized and each object was only highlighted once. On completion of the task, participants were thanked and debriefed.

\section{Results}

Accuracy of memory for non-shifted objects as a function of location. 
Figure 3 shows the means (and $S E$ s) for percentage of Yes responses as a function of whether the objects were present at study and whether they were in schema expected, unexpected, or irrelevant locations. In order to address the question of whether schema-relevant objects in unexpected locations demonstrate similar distinctiveness effects to those found in earlier research with schema-irrelevant objects (Brewer \& Treyens, 1981; Lampinen et al., 1991; Mäntylä \& Bächman, 1992; Pezdek et al., 1989), a mixed 2(Condition) x 2(Study: present, absent) x 3(Location: expected, unexpected, irrelevant) ANOVA was conducted on the proportion of Yes responses. Only the objects present at study that remained in their original locations, and the objects added in as foils in test photographs, were included in the analysis.

As expected, there was no significant main effect and no significant interaction effects involving the between-subjects factor of condition. Participants in both conditions experienced the same stimuli in terms of non-shifted objects. There was a main effect of location, driven by the far higher false memory rates for schemarelevant objects in expected locations, $F(1.6,59.6)=27.1, p<.0001, \eta_{p}^{2}=.42$, and a main effect of study, whereby the proportion of Yes responses was far higher for objects present at study versus foils, $F(1,38)=431.6, p<.0001, \eta_{p}^{2}=.92$. As predicted, there was a significant interaction between location and study, $F(1.6,61.4)$ $=23.2, p<.0001, \eta_{p}^{2}=.92$. Planned contrasts demonstrated that this effect was due to the predicted higher level of false memories for schema-relevant objects presented in expected locations at test, relative to schema-relevant objects presented at unexpected locations, $t(39)=5.8, p<.0001$, mean difference $=35.6 \%, 95 \%$ CI $[23.1$, 48.2], $d=.9$, and also relative to schema-irrelevant objects, $t(39)=8.1, p<.0001$, mean difference $=38.3 \%, 95 \%$ CI $[29.8,47.3], d=1.3$. There was no reliable difference between levels of false memories for schema-relevant objects in 
unexpected locations and schema-irrelevant objects $(p=.5)$. There were no reliable differences between levels of true memories for schema-relevant objects at expected or unexpected locations, or these objects and schema-irrelevant objects.

\section{Accuracy of memory for shifted objects as a function of location.}

Figure 4 shows the means (and $S E$ s) for percentage of correct responses as a function of whether the objects were originally present at study in schema expected, unexpected, or irrelevant locations, before being shown in different locations in the test photograph. In order to address the question of whether schema-driven false memory effects are detectible for object-location bindings, a 2(Condition) $\mathrm{x}$ 3(Location) ANOVA was conducted on the proportion of accurate responses. There was no reliable main effect for condition $(p=.5)$. There was a significant main effect of location, $F(1.6,62.2)=8.1, p=.002, \eta_{\mathrm{p}}^{2}=.12$, driven by the predicted significant interaction between Condition $\mathrm{x}$ Location, $F(1.6,62.2)=3.9, p=.03, \eta_{\mathrm{p}}^{2}=.09$. Here, there was a higher level of false memories for schema-relevant objects moved from unexpected to expected locations, relative to unexpected-to-different-unexpected shifts. Planned contrasts confirmed this pattern of results with the only significant difference between conditions at each location being in the comparison of objects that were originally in unexpected locations, $t(38)=2.3, p=0.03$, mean difference $=$ $18.8 \%, 95 \%$ CI $[35.6,1.9], d=.7$.

\section{Discussion}

Consistent with prior research using real schema-inducing room environments (Brewer \& Treyens, 1981; Lampinen et al., 2001; Mäntylä \& Bächman, 1992; Pezdek et al., 1989), we obtained high levels of both true and false memories for schemaconsistent objects in expected locations, together with high levels of true memories coupled with low levels of false memories for schema-irrelevant items, as predicted 
by distinctiveness effects. Thus, the use of photographic stimuli did not act to reduce these effects (see also discussion in Pezdek et al., 1989). Our results also demonstrate that a schema-relevant object in an unexpected location seems to attract similar levels of attention as schema-irrelevant objects because there was no difference in the levels of true and false memories between consistent objects in unexpected locations and irrelevant objects. Despite this "pop-out" effect for schema-relevant objects in unexpected locations, there were higher levels of false memories for the location of these objects when seen in schema-expected locations at test, relative to seeing these objects in different unexpected locations. This result was predicted by our analysis of schema-driven false memory effects acting on binding between elements, due to evoked schema-expected bindings leading to source memory confusions, acting independently of memory for the elements in isolation.

An alternative account for the pattern of results obtained for the shifted objects cannot be ruled out however, one based on analyses of data utilizing an adaptation of the source memory paradigm (Batchelder \& Riefer, 1990; Johnson et al., 1993). Typically in these paradigms, participants study items linked to at least two different sources (e.g., two lists of behaviors associated with two different individuals such as a skinhead and a priest; Sherman \& Bessenoff, 1999) and are then required to identify items as old or new from a set including foils, followed by a judgement as to the source of the item if identified as old. Some studies (Bayen \& Kuhlmann, 2011; Bayen, Nakamura, Dupuis, \& Yang, 2000, Experiment 1; Konopka \& Benjamin, 2009; Mather, Johnson, \& De Leonardis, 1999) obtain a misattribution bias whereby stereotypically inconsistent pairings are misattributed to the consistent source (e.g., a prosocial behavior originally linked to the skinhead is misremembered as belonging to the priest) but often no schema-driven source misattribution bias is 
found (Bayen \& Kuhlmann, 2011; Cook et al., 2003, Experiment 2; Hicks \&

Cockman, 2003; Kleider, Pezdek, Goldinger \& Kirk, 2008; Kuhlmann, Vaterrodt, \&

Bayen, 2012, Experiment 1). Bayen and Kuhlman (2011) argue that null effects are due to participants being aware of the equal probabilities during encoding. In studies where the equal probabilities are less transparent, a misattribution bias can be explained, using multinomial processing tree modeling of the data, by guessing biases only occurring in the absence of true memory for the source. Specifically, Bayen and Kuhlman suggest that true recall levels for the source are equal across expected and unexpected conjunctions, as well as neutral items if present. However, when participants do not have true recall, they guess in a positively biased manner towards expected conjunctions (e.g., endorsing that a priest was the source of a prosocial behavior). ${ }^{1}$

Following similar arguments in the recognition paradigm utilized in Study 1, it is possible that the level of true memory for object-location bindings across all the objects and locations was between 50-60\% approximately, the level of accuracy obtained for the schema-relevant objects shifted from unexpected to expected locations. Other responses constitute guesses, in the absence of actual memory for the original object-location pairing. If these guesses are not biased in terms of yes/no responses , then levels of "no" responses (the correct response to the question "was

\footnotetext{
${ }^{1}$ In terms of understanding schema-driven false memory effects acting on binding between elements, the source-monitoring paradigm presents a fundamental limitation relative to the novel paradigm we utilize in the present research. The sourcemonitoring paradigm pits memory for schematically-expected bindings (e.g., "priest gave up seat on the bus") against memory for schematically-unexpected bindings (e.g., "priest - shoved to front of queue"). This comparison potentially conflates two different mechanisms acting on memory. In the case of expected bindings, low attention may make both the elements and their bindings less memorable. In the case of unexpected bindings, only the bindings may be less memorable, due to competition effects as opposed to low attention, as we hypothesize.
} 
this object in this place before") would be expected to be between $70-80 \%$, i.e., approximately $50 \%$ true memory for the original correct object-location pairing, plus $25 \%$ guess for a correct "no" response. Both the shifted irrelevant objects, and the relevant objects shifted from one unexpected location to another, attracted $70-80 \%$ correct responses, which would be consonant with this veridical memory plus unbiased guessing account. In the case of seeing a schema-relevant object in an expected location at test however, a schema-driven bias towards guessing "yes" may occur, such that the level of correct "no" responses remains between 50-60\%, due to veridical memory only. Although this account contains a schema-driven effect, it does not depend on evoked schematically-relevant object-location bindings competing with memory for the unexpected binding seen during learning.

In addition to the potential guessing biases outlined above, some of the items that were shifted at test will not have been processed during study, thus effectively being new stimuli for participants (e.g., approximately 15\% failure to recognize old non-shifted objects, see Figure 3). There will be a bias to endorse these items as old if they are schema-relevant objects seen in schema-expected positions, relative to irrelevant objects or schema-relevant objects seen in unexpected positions, thus accounting for a portion of the difference between conditions.

In order to try to distinguish the competition with the evoked expected bindings account from the guessing account of the results of Study 1, in Study 2 we devised a recall version of the task. This version also addresses the problem of distinguishing object-location binding memory failures from object memory failures. In Study 2, exactly the same initial study stimuli were used as in Study 1, but then participants were presented with a photograph of the room without any of the target objects present. The 12 target objects were presented as icons on a side bar and 
participants were asked to select the objects they thought had been present (i.e., an object recognition task), and then to drag those objects to their remembered locations in the room (i.e., a location recall task). If we are correct in our analysis of why participants show relatively high levels of false memories for unexpected objectlocation bindings, then there should be a robust difference in the level of correct placements of schema-relevant objects originally viewed in unexpected locations, relative to schema-irrelevant objects, and the greater erroneous placements of the schema-relevant objects should be largely in expected locations. This predicted lower level of correct placement of schema-relevant objects originally seen in unexpected locations should occur despite similar levels of object recognition such as those obtained for the irrelevant objects, given the similarity in distinctiveness effects obtained in Study 1 for the non-shifted objects between schema-relevant objects in unexpected places, and schema-irrelevant objects.

Predictions concerning the schema-relevant objects originally seen in expected locations are more tentative in terms of object recognition. It could be argued that there will be lower levels of recognition of objects that were originally in expected locations, relative to those in unexpected locations or schema-irrelevant objects, due to the lower level of processing they receive during study. Pezdek et al. (1989) did find higher levels of recognition for schema-irrelevant objects relative to schemarelevant objects when tested from a written list of objects, half of which were originally seen in vivo in a room scene. It is possible that when the recognition task does not involve exact reinstatement of the initial learning situation (e.g., a change from seeing the real object in a room to seeing a written label), the lower level of processing occurring at encoding due to schematic consistency has similar effects on memory performance as that found with recall tests (i.e., poorer performance for 
schema-relevant items; see Rojahn \& Pettigrew, 1992; Stangor \& McMillan, 1992). In Study 2, when the objects are seen as icons in canonical orientations and the task is to drag the icons to remembered locations, there may be sufficient differences between the encoding and test situation to support a prediction of lower levels of recognition for schema-relevant objects originally viewed in expected locations relative to objects in unexpected locations, and schema-irrelevant objects. Finally, as was found in Study 1 , it can also be predicted that there will be higher levels of false recognition for schema-relevant foils relative to schema-irrelevant foils (Lampinen et al., 2001; Pezdek et al., 1989).

In terms of recall of location of correctly recognized schema-relevant objects that were in expected locations, it can be predicted that levels of correct recall should be reliably lower than for the schema-irrelevant objects because of the relatively low level of attention given to these object-location pairings during study. Guessing biases will not be particularly influential here because there are generally multiple possible expected locations available (e.g., a toaster may be placed on any part of the kitchen work-surfaces) and regardless of which one is shown, it can still be in an expected location, although not necessarily in the location chosen in the photograph studied (e.g., the work-surface to the right of the sink). It follows from this prediction that the majority of placement errors should be in schema-expected locations.

If guessing biases can account for the findings of Study 1, then levels of recall for location should be similar across all categories of objects, with the majority of errors in the schema-relevant objects being in expected locations. Unlike in Study 1 where similar actual levels of recall of object-location pairings can be masked by guessing biases towards "yes" responses when objects are viewed in expected 
locations, when objects have to be placed in the correct location from multiple possibilities, guesses can be distinguished from true recall.

\section{Study 2}

\section{Method}

\section{Participants.}

Participants were either first year psychology students gaining partial course credit for research participation, or non-psychology students from different levels of study at the university gaining small monetary compensation for participation. There were 32 participants ( 26 females, mean age $=19.2$ years, range $18-27$ years $)$, with a further two participants tested but excluded from the final sample due to technical problems; one with saving data and the other with a program freeze during testing. This sample size is comparable to recall studies in related research (Pezdek et al., 1989). The study was approved by the University Ethics Committee and conformed to British Psychological Society and American Psychological Association ethical guidelines.

\section{Stimuli.}

The stimuli used in this experiment were the color digital photographs used in Study 1, (i.e., the original study scenes for the bathroom, kitchen, living room, and office). Half the participants saw one set of schema-irrelevant objects during study (7.-9. in Table 1) and the other half saw another set (10.-12. in Table 1). Additionally, half the participants saw the unexpected locations from list 1 (see Table 1) and half saw the list 2 unexpected locations (Table 1). Which of the 3 versions of the scene they saw in terms of the objects taking the roles of being in expected or unexpected locations was randomly selected for each participant (Figure S1). Stimuli were 
presented using the same PsyScript program (Slavin, 2003-14) as Study 1. For the test phase however, a switch was made to a Keynote file that contained 4 slides, one of each room (photographs again standardized to $1300 \times 864$ pixels), without any of the 12 objects associated with that room being present. The photographs were all taken on the same day with the same camera tripod position and settings as the relevant room photographs used in Study 1. The individual photographs of all the objects (12 per room, see Table 1) used for the normative study of object schemaconsistency, were turned into icons of width 64 pixels, with varying heights to preserve the image height-width ratios. The object icons were placed in two rows of 6 objects on a bar to the right of the room photograph to which they were associated. The order of placement was randomized prior to testing for each participant. Figure 1 (bottom panel) provides an example of a kitchen slide after one participant has clicked and dragged on remembered objects, after viewing the photograph in the top panel of Figure 1.

For the purposes of training participants on the requirements of the task, a practice printed and laminated photograph was used that depicted a garden scene with 3 target objects: a football on the grass (e.g., schema-relevant object in an expected location), a garden gnome on top of a fence (e.g., schema-relevant object in an unexpected location), and a cardboard packing box (e.g., schema-irrelevant object). A laminated test photograph was also used that did not contain the 3 target objects, where these objects were cut out and laminated individually along with a $4^{\text {th }}$ object (e.g., a garden slide) added as a further object icon that served as a foil.

Following the training, the room photographs were presented in PsyScript running on a 15.4 inch MacBook Pro laptop. After 15s of the same distractor task described for Study 1, a change was made to the relevant Keynote slide by the 
experimenter while the participant looked away to a fixation point on the wall behind them. Once the participant had finished clicking and dragging objects to their remembered locations, PsyScript was used to present the next room, with the switch to Keynote repeated until all 4 rooms were presented.

\section{Design.}

As with Study 1, the main within-subject factor was the location (expected, unexpected, and irrelevant) in which an object was placed in the original study image. Whether the object was present at study, or only present at test as an individual icon, was also varied. In terms of those objects present at study, there were two dependent variables examined. The first was the percentage of correctly recognized objects and the second was the percentage of correctly placed objects. An analysis of erroneous placements was also made in terms of whether the placement was schema-expected (only applying to schema-relevant objects), a substitution error (e.g., a placement was made where another object had been in the original image), or neither of these categories. Additionally, for both schema-relevant and schema-irrelevant foils presented as icons in test stimuli, the proportion of falsely recognized objects was analyzed to address the prediction that more schema-relevant objects would be falsely recognized than schema-irrelevant objects. Placements of falsely recognized objects were also analysed into categories of schema-expectedness (for schema-relevant objects), substitutions, or "other".

All placements were analysed and classified by a main observer (ARL) and also examined by an independent observer naïve to the background and hypotheses of the study. In general, a categorical approach was used in terms of object placements (Hess \& Slaughter, 1990). The work-surfaces in the kitchen naturally segmented into 4 zones, left and right of the sink and left and right of the stove (see Figure 1). Thus 
for an object that was originally placed to the right of the sink, all other zones would be considered as incorrect placements. Other instances of natural segmentation occurred with table surfaces and shelves, the hearth in the living room scene, corners and the middle section of the bath in the bathroom scene, and left and right sides of the sink and cistern. In the office scene, there was an extended desk surface along one wall that naturally segmented into a back, middle, and near sections based on an angular wall contour to accommodate windows. For areas that had less clear segmentation (e.g., floor areas) for a placement to be correct it had to be adjacent to the correct feature near a wall (e.g., the bin to the near section of desk), or if more centrally placed originally (e.g., walking boots on the floor in kitchen scene), the placement had to be between the correct features (e.g., between table and stove for the boots). All errors and their classifications are listed in Tables S1-S3. These can be cross-referenced with the correct locations listed in Table 1. Out of a total of 604 placements, there were 6 disagreements between coders (1\%). In these instances, placements were borderline (e.g., the phone being placed on the boundary between front and middle desk segments). It was decided to retain the codings by ARL because they were more conservative with regard to the hypotheses in 4 out of the 6 instances (e.g., 'phone placement coded as correct).

For all analyses, tests of significance were 2 -tailed and a $p$-value of $<0.05$ was used to reject the null hypothesis. The Greenhouse-Geisser correction for unequal variances was applied where relevant in all analyses.

\section{Procedure.}

The task consisted of a study phase, followed by a distractor task, followed by a memory test. Participants were aware that their memory for objects and their location in scenes would be tested. Participants were instructed that they would be 
presented with 4 scenes for 12 seconds each.. Following a 15 s distractor task after the presentation of one of the scenes, participants were asked to turn and look at a marked spot on the wall behind them. They sat in a desk-chair so as to be able to swivel around quickly. While they were not looking, the experimenter changed programs to the relevant room slide and then asked participants to turn back to face the laptop. This program change process took between $10-17 \mathrm{~s}$. Because the order in which room scenes was presented by PsyScript was pseudo-randomized, the experimenter needed to sit adjacent to the participant in order to know which slide to change to for the memory test. Once participants were engaged in the test phase, the experimenter read until the participant signalled that they had finished and were ready to continue to the next presentation of the next room scene.

Prior to the study, the procedure was rehearsed using printed and laminated materials (see Stimuli section above). Participants studied the garden image, waited for a short interval, and were shown a photograph of the garden with the 4 target object icons to the right side. Participants placed the objects they recognized. None of the participants placed the slide icon and they were given feedback that there may be object icons in the main study that were not present originally. Participants were reassured that the object icons on the right side bar were representations of the objects only, so when they were dragged into the room photograph in the main study, they would not appear to be the right size or orientation; rather, they were markers for the remembered location.

The task took approximately 15 minutes to complete. On completion of the task, participants were thanked and debriefed.

\section{Results}

\section{Correct object recognition as a function of location.}


Figure 5 shows the means (and $S E \mathrm{~s}$ ) for percentage of correctly recognized objects as a function of whether they were in schema expected, unexpected, or irrelevant locations. In order to address the prediction that schema-relevant objects studied in expected locations will be less recognized than either relevant objects in unexpected locations, or irrelevant objects, a within-subject ANOVA with location as the factor was conducted. There was a significant effect of location, $F(2,62)=10.44$, $p<.0001, \eta_{\mathrm{p}}^{2}=.25$. Planned contrasts showed that the schema-relevant objects originally seen in expected places were more poorly recognized than schema-relevant objects seen in unexpected places, $t(31)=3.5, p=.001$, mean difference $=13.7 \%$, $95 \%$ CI $[5.7,21.6], d=.6$, and than schema-irrelevant objects, $t(31)=4.6, p<0.0001$, mean difference $=15.1 \%, 95 \%$ CI $[8.3,21.9], d=.8$. There was no difference in correct recognition levels for schema-consistent objects originally in unexpected locations and schema-irrelevant objects $(p=.7)$.

\section{Correct location recall as a function of study location.}

Figure 5 also shows the means (and $S E$ s) for the percentage of correctly placed objects following their correct recognition. In order to address the prediction that there would be fewer correct placements of schema-relevant objects studied in unexpected locations relative to schema-irrelevant objects, a within-subject ANOVA was conducted with location as the factor. There was a significant location effect, $F(2,62)=5.05, p=.009, \eta_{\mathrm{p}}^{2}=.14$. Planned contrasts indicated that the only reliable difference occurred in the comparison between schema-relevant objects studied in unexpected locations and schema-irrelevant objects, $t(31)=-3.7, p=.001$, mean difference $=13.6 \%, 95 \% \mathrm{CI}=[6.0,21.2], d=.6$. The difference between placement of schema-relevant objects studied in expected locations and schema-irrelevant objects was not reliable $(p=.3)$ and there was also no reliable difference relative to 
schema-relevant objects studied in unexpected locations $(p=.06)$, although this was marginal. This relatively high level of correct placement of schema-relevant objects originally seen in expected locations went against predictions that performance would be poor due to low levels of attention to such consistent bindings, a point we return to in the discussion.

The types of errors made were analyzed and classified according to whether placements occurred to schema-expected locations for schema-relevant objects and also whether they represented object substitution errors. A full list of all errors classified as schema-expected errors, or otherwise, is provided in Tables S1-3 as supplementary material. For schema-relevant objects originally studied in expected locations, $77.8 \%$ of errors ( 28 out of a total of 36 ) occurred to alternative expected locations (Table S1). One of the errors to a schema-expected location was also a substitution error. For schema-relevant objects originally studied in unexpected locations, $81.4 \%$ of errors (48 out of 59 ) were to schema-expected locations (Table S2). Five of these errors to expected locations were also substitution errors. Of the remaining 11 errors to unexpected locations, 5 were substitution errors. There were 44 placement errors in total for the schema-irrelevant objects, 5 of which were substitution errors (Table S3).

\section{False object recognition as a function of schema-relevance of foils.}

The mean proportion of false recognition of schema-relevant foils was $23.4 \%$ $(S E=4.1 \%)$ with the mean proportion for irrelevant foils being 3.6\% $(S E=2.6 \%)$. This difference was significant, $F(1,31)=36.46, p<.0001,, \eta_{\mathrm{p}}^{2}=.54$. The large majority of the falsely recognized schema-relevant foils were placed in schemaexpected locations $(54 / 60)$. Otherwise, 3 placements were substitution errors and 3 placements were to unexpected locations. 


\section{Discussion}

The results of Study 2 demonstrate the full paradoxical effect predicted by our analysis of potentially independent schema-driven false memory effects acting on individual elements of an event and the binding between elements. The effect of seeing a schema-relevant object in an unexpected location was to make the individual object more memorable, as evidenced by significantly higher recognition levels relative to schema-relevant objects seen in expected places. Despite this greater memorability for the object, levels of correct placement were significantly lower than for the irrelevant objects, as predicted by our analysis, but not by traditional formulations of distinctiveness effects that do not distinguish between elements and their bindings (Schacter et al., 1999; Schank, 1982, 1999). The large majority of errors were placements to expected locations, as predicted by our account of competition between the actual object-location pairings, and evoked, schematically expected pairings. In addition, our results demonstrate that actual levels of true memory for object-location pairings are not equal across different categories of object, with those for irrelevant objects being higher. Therefore it is unlikely that the results of Study 1 can be accounted for by postulating equal levels of true memory across all location categories, with guessing biases leading to differences in results, or from biases to endorse non-recognized objects as old.

One possibility that needs to be considered is that because there is a tendency to falsely recognize schema-relevant foils compared to irrelevant foils, some of the objects that were classified as having been correctly recognized may have in fact been guesses. Therefore, differences in levels of correct placements between schemairrelevant objects and both types of schema-relevant objects could be due to the noise introduced by this higher level of guessing towards schema-relevant objects generally. 
Although such guessing could make some contribution to the pattern of results obtained, it is unlikely to be able to explain the full effect. This is because the higher level of object recognition of schema-relevant objects viewed originally in unexpected locations should lead to better placement performance relative to schema-relevant objects viewed in expected locations, as guessing would be spread evenly across the two categories. However, this was not found. Thus, the pattern of results obtained in Study 2 with regard to schema-relevant objects viewed in unexpected locations is best explained by schema-driven false memory effects acting independently on objectlocation bindings, despite superior object memory.

One unexpected result was the relatively high level of correct placement of schema-relevant objects originally viewed in expected places. Theoretically, we predicted that levels of correct placement would be lower than for schema-irrelevant objects due to low levels of processing and attention not only to the objects themselves but to the schema-expected pairing of object with location. While a less counterintuitive prediction than that occurring for unexpected pairings, it is nevertheless a novel prediction, as prior studies have focused on distinctiveness effects for individual schema-relevant objects rather than bindings, for example by introducing token changes in objects (Mäntylä \& Bächman, 1992; Pezdek et al., 1989). It is therefore important to account for the finding of relatively good placement performance in the face of low levels of recognition of individual schema-relevant objects seen in expected locations.

One methodological possibility that could have accounted for the relatively high proportion of correct placements of schema-relevant objects originally seen in expected places was that the locations that were used in our stimuli may have matched preferred default places for those items (e.g., fruit bowl on table), such that even with 
no memory component involved, those objects would be likely to be placed in those locations. Although for most of the schema-consistent objects there were multiple possible expected locations, we wondered if for a few objects this would not be the case and, therefore, that guesses were inflating the proportion of correctly placed objects originally seen in expected locations. We addressed this issue in Study 3 by first of all asking a group of 12 participants to place the schema-relevant objects used in the study within the room photographs in locations they considered usual for those objects. No memory component was involved; this normative study allowed us to establish if there were default locations that matched those locations used in the stimuli in Studies 1 and 2. A small subset of objects were identified where there was a match between default placements and the locations used in Studies 1 and 2. We then reanalyzed the data from Study 2, completely excluding the objects where default placements matched those used in the memory stimuli. Our expectation here was that all of the same effects would be found as in the analysis reported for Study 2, except that the level of correct placements for schema-relevant objects seen in expected places would now be significantly lower relative to irrelevant objects, due to the exclusion of guesses scored as correct for objects where the default placement matched the placement in the memory stimuli (e.g., fruit bowl on table). We also replicated Study 2 with 32 new participants, to establish the reliability of results. The reanalysis of Study 2 data, the new data for the replication in Study 3, and the pooled results, are all presented, where in all datasets the 7 objects identified in the normative study were excluded when deriving the dependent measures.

\section{Study 3}

\section{Method}

\section{Participants.}


Participants were either first year psychology students gaining partial course credit for research participation or students from different levels of study at the university gaining small monetary compensation for participation. There were 12 participants ( 9 females; mean age $=25.3$ years, range $18-38$ years) in the normative study investigating default placements of schema-consistent objects, and 32 participants ( 24 females; mean age $=20.0$ years, range $18-26$ years) in the replication of Study 2.

\section{Stimuli.}

In the normative study, the same Keynote slides utilized in Study 2 were used. The order in which the rooms were presented in the file was pseudo-randomized and the order in which the objects appeared as icons on the right of the room photographs was randomized for each participant. Only the 6 schema-consistent target objects used in Studies 1 and 2 were presented. The stimuli for the replication study were identical to those used in Study 2.

\section{Design and Procedure.}

In the normative study, participants were told that they would see some materials originally used in a memory study and that it was necessary to ascertain the locations at which certain objects would be placed in a room scene at a baseline level. They were then shown the first slide in the Keynote file in which the room photograph with associated schema-relevant icons was displayed. They were asked to click on each of the 6 objects in turn and drag them to a location they thought was usual for that object. They were reassured that the size and orientation of the object would look odd and that the icons were simply markers for locations. They were asked to work their way sequentially through the 4 slides of the 4 different rooms and 
to signal to the experimenter when they had finished. On completion of the study, they were thanked and debriefed.

The number of times (out of a maximum of 12) that a participant placed an object in the same location as that used for the expected locations in Studies 1 and 2 is displayed in square brackets in Table 1 . There were 7 objects where the majority of placements were at the same location as that used in Studies 1 and 2. These were the scales, toilet brush, fruit bowl, pan, TV, painting, and 'phone.

In the replication study, the design and procedure was identical to that in Study 2, except that the seven objects listed above were excluded completely from analyses when deriving proportions of correct recognition, recall, and false recognition. We also report a re-analysis of the Study 2 data excluding these objects, as well as a pooling of Study 2 and Study 3 data with these exclusions, to maximise the reliability and replicability of the results (a list of all placement errors for the replication study is provided in Tables S1-S3, where errors on the full set of objects are reported for completeness, although excluded objects are identified in italics).

\section{Results and Discussion}

The top panel of Figure 6 displays the percentage of correctly recognised objects in the Study 2 reanalysis, the Study 3 replication, and the pooled data, with full exclusion of the 7 objects where the schema-expected locations used in the memory stimuli matched default placements. The higher level of recognition of schema-relevant objects in unexpected locations, as well as schema-irrelevant objects, relative to schema-relevant objects seen in expected locations was robustly replicated across the 3 datasets. For the pooled data set, a single factor ANOVA with the 3 levels of location was conducted on the proportion of correctly recognized objects, which showed a significant effect of location, $F(2,126)=13.15, p<.0001, \eta^{2}=.17$. The 
same pattern of results was obtained for the Study 2 reanalysis and Study 3 replication, with effect sizes of .23 and .13 respectively. Planned contrasts on the pooled data showed that the schema-relevant objects studied at expected locations were poorly recognized relative to the other two categories of objects (largest $p=$ .001). There was no reliable difference between schema-relevant objects studied at unexpected locations and irrelevant objects $(p=.18)$. The same pattern of effects was seen in the Study 2 and Study 3 data sets. Thus, as expected, the recognition data remains similar to the analysis using the full set of objects used in Study 2.

The bottom panel of Figure 6 displays the percentage of correctly recalled locations of objects in the Study 2 reanalysis, the Study 3 replication, and the pooled data, with full exclusion of the 7 objects where the schema-expected locations used in the memory stimuli matched default placements. In the pooled dataset there was a significant location effect, $F(1.7,108)=5.76, p=.004, \eta_{\mathrm{p}}^{2}=.09$, Planned contrasts showed a significant difference between schema-relevant objects studied at expected locations and irrelevant objects, $t(63)=3.31, p=.002$, mean difference $=13.79 \%$, $95 \%$ CI $[5.47,22.12], d=.51$, as well as schema-relevant objects studied at unexpected locations and irrelevant objects, $t(62)=2.88, p=.006$, mean difference $10.04 \%, 95 \%$ CI $[3.06,17.2], d=.41$. There was no difference between the two schema-relevant object categories $(p=.40)$. Although the pattern of results was similar for the Study 2 reanalysis and the Study 3 replication, the location effect was marginally significant in both cases $(p=.06$ and .09 respectively, with effect sizes of .23 and .10), due to lower power.

These results suggest that levels of correct placement of schema-relevant objects originally seen in expected locations that was found in Study 2 may have been somewhat inflated by the match between baseline preferences for placing certain of 
the objects used in the study and the expected locations that we selected in the memory stimuli. The levels of correct placements found in Study 3 in the light of the baseline data obtained in the normative study are more in keeping with predictions that correct placement would be relatively lower than for irrelevant objects, due to lower levels of processing on schema-expected object-location pairings during study of the room scenes. An analysis of placement errors in the Study 3 replication (Tables S1-3) found that $87.5 \%(42 / 48)$ of erroneously placed schema-relevant objects viewed in expected locations were to alternative expected locations, similar to Study 2.

The levels of correct placement for schema-relevant objects studied in unexpected locations remained similar to that obtained with the full set of objects in Study 2, with this level being significantly lower than for the schema-irrelevant objects, despite similar object recognition levels. An analysis of errors in the Study 3 replication (Table S2) showed that $82.69 \%(43 / 52)$ of these errors were to schemaexpected locations, again similar to Study 2. Thus, the prediction that memory for object location-binding for schema-relevant objects in unexpected locations would be relatively low due to competition from evoked consistent bindings, has been further supported in Study 3. Interestingly, there was also occasional evidence of errors where a schema-irrelevant object was substituted by a schema-relevant object more in keeping with a location (e.g., the computer was placed on the desk where in fact the climbing shoes had originally been viewed). It is possible in such cases that a location evokes an object during encoding, which can then compete with the schema-irrelevant object-location binding. Alternatively or additionally, there may be memory that an unspecified object was present at that location, and then a "best-guess" is made from the choice of objects available. 
Finally, the levels of false memories for schema-relevant foils remained similar in the Study 2 reanalysis and Study 3 replication study (see Figure 7). For the pooled data, the difference between false recognition of schema-relevant versus irrelevant foils was significant, $\mathrm{F}(1,63)=48.5, \mathrm{p}<0.0001, \eta_{\mathrm{p}}{ }^{2}=.44$. For the schemarelevant foils in the Study 3 replication, 97.9\% (46/47) were to schema-expected locations (Table S3).

\section{General Discussion}

Since the founding work of Bartlett (1932) on the multiple effects of schemata on the processing and remembering of new information, robust schema-driven effects have been established. These effects, which we summarized using the term distinctiveness effects, show the opposing trends of poorer memory for schemarelevant items (with the converse of better memory for irrelevant items) due to automaticity of processing of relevant items, together with lower thresholds for accepting schema-relevant items as having been present. In this research, we presented a novel theoretical analysis of how distinctiveness effects can act independently for elements of events and their bindings. We also developed a paradigm to specifically measure any schema-driven false memory effects acting on binding between elements, whereby a change between encoding and test from an unexpected-to-expected binding is pitted directly against an unexpected-to-differentunexpected change. Using this paradigm within the context of object-location bindings in schematic room scenes, we were able to demonstrate a robust false memory effect for changes to expected bindings. Our suggestion that this effect is driven by competition from evoked expected bindings was further strengthened in Studies 2 and 3 where participants showed superior recognition of items that had formed unexpected bindings, but relatively poor placement of those items in their 
correct locations (correct bindings), with errors occurring to schema-expected locations. Because recognition was similar for schema-relevant items that were in unexpected locations and irrelevant items, but irrelevant items were placed with higher accuracy, it is unlikely that our data can be explained by a model positing equal levels of accurate memory for object-location bindings, with schema-driven guessing biases accounting for any differences in performance (Bayen \& Kuhlmann, 2011).

A question arises as to the generality of our model positing independent distinctiveness effects for elements and their bindings. Because we suggest that the possibility of independent distinctiveness effects arises as a consequence of the action of temporal lobe memory systems acting to bind together different aspects of events stored in separate brain systems (Horner \& Burgess, 2013, 2014; McClelland et al., 1995), it should be possible to demonstrate such effects over a range of types of material, beyond object-location bindings. Guided by our theoretical analysis and results, we re-examined findings from the literature using the source-monitoring paradigm where schematically relevant information is presented at encoding. If participants are not cognizant of the actual and equal probabilities of different sources being correct in such studies (Bayen \& Kuhlmann, 2011), we would expect a pattern of results of greater recognition of items forming unexpected bindings as being "old" rather than "new", but similar levels of accurate source memory, as obtained in our studies, between schema-expected and schema-unexpected bindings, assuming the recognition task did not directly reinstate encoding conditions (as in studies 2 and 3).

A study by Kleider and colleagues (Kleider et al., 2008) conformed to these design characteristics, and due to the inclusion of filler items specifically aimed at making the structure of the task less transparent, may have avoided artifacts due to 
participants being aware of the task structure (Bayen \& Kuhlmann, 2011). In this study, participants watched short videos of two characters, a male handyman and a female homemaker, carrying out schema-expected actions, schema-unexpected actions, and neutral action fillers (e.g., drinking water). At test, after 2 minutes of distractor tasks, sets of actions that were originally performed by the expected or unexpected actor, together with foils, were presented in written form, so the recognition context did not reinstate learning conditions. Participants had a higher hit rate in terms of old/new judgements for actions that had been performed by the schema-unexpected actor, but there was no difference in the accuracy of their source memory between correctly remembered actions performed by the schema-expected actor versus the schema-unexpected actor. The authors found it hard to account for these results within existing theoretical frameworks, but they are consistent with our model and findings.

Future research using a forced-choice recognition paradigm may be helpful for establishing whether the competition effects that we posit between the veridical unexpected, and associatively evoked expected, object-location bindings are occurring at the earliest stages of encoding, or following encoding of the veridical binding. Low performance when the veridical unexpected binding is present among foils may indicate interference at the level of encoding, rather than the more usual view of source memory errors as arising from associatively evoked items following encoding. ${ }^{2}$ Eye-tracking data on how attention is being allocated during initial study of scenes would also provide more direct evidence for the proposed difference in attentional capture between schema-relevant objects in expected versus unexpected locations, as has been successfully demonstrated for relevant versus irrelevant items

\footnotetext{
${ }^{2}$ We thank one of our reviewers, Jason Hicks, for this suggestion.
} 
within scenes in prior research (e.g. Loftus \& Mackworth, 1978). Such data may also help to corroborate whether objects were scanned, however briefly, during study, providing more confidence in correct judgements during recognition and recall tests.

There has been a recent increase in theory and research concerning the brain systems underlying the interaction between schematic knowledge and episodic memory (Preston \& Eichenbaum, 2013; van Kesteren, Ruiter, Fernández, Henson, 2012), with the ventromedial prefrontal cortex identified as a key region mediating between cortical networks thought to underpin schematic knowledge on the one hand, and temporal lobe (especially hippocampal) areas underpinning specific event memory on the other. In terms of understanding the neural basis of schema-driven memory distortions, Warren and colleagues (Warren, Jones, Duff, \& Tranel, 2014) found that patients with ventromedial prefrontal cortex damage showed unimpaired true memory for lists of semantically-related words relative to controls, but lower levels of false memories for semantically-related critical lures. Because memory for items actually presented on these lists was not mediated via schemas activated during list presentation (i.e., in these lists, variation in associative strength from the list items themselves to the non-presented falsely remembered item is not correlated with true memory; see Roediger, Watson, McDermott, \& Gallo, 2001), only false recall is mediated by schema activation. These findings are consistent with those of Aminoff, Schacter, and Bar (2008) who found that higher activation of left medial prefrontal cortex (as well as bilateral activation of retrosplenial and lateral parietal cortices) during encoding of items strongly associated with a context, was related to later false alarms to new items linked to the evoked context, relative to correct rejections of such items. In terms of schema-unexpected bindings, Straube and colleagues (Straube, Meyer, Green, \& Kircher, 2014) found greater activation in anterior and posterior 
cingulate cortices, as well as anterior thalamic areas, congruent with heightened attention and surprise reactions, relative to schema-expected bindings, for correctly remembered unexpected sentence-gesture pairings.

These neuropsychological and imaging studies may be considered as preliminary steps to understanding the neural basis of schema evocation, as well as heightened attention to schema-mismatching stimuli. In the paradigms utilized in the present research, as well as studies such as Kleider et al. (2008), it would be expected that stimuli containing schema-unexpected bindings between elements would both highly activate cortical networks (schema evocation), ventromedial prefrontal areas, and lead to surprise "mismatch" reactions, potentially involving cingulate and thalamic areas. How the interplay between activations in these areas and temporal lobe systems results in either correct memory or schema-driven false memory could be informative in terms of further understanding schema-driven false memory effects, using suitably adapted paradigms for imaging research.

The present research may have implications for understanding vulnerabilities in eyewitness testimony. This is because we found a particular vulnerability for remembering unexpected conjunctions of objects and locations in the face of superior memory for the object itself, using naturalistic scenes. It is important to extend this work to the complex event stimuli used in applied forensic research (e.g., Aizpurua et al., 2009; Migueles \& García-Bajos, 1999) in order to establish whether such vulnerabilities could exist in potential misattributions of actions or dialogue in a schema-congruent fashion. Additionally, it is well known that jurors, once they have developed a schema for the evidence being presented in a trial, not only tend to remember schema-relevant information and ignore schema-irrelevant facts, but also frequently misremember "facts" not in evidence but that are schema-relevant 
(Huntley \& Costanzo, 2003; Pennington \& Hastie, 1993). Of course these errors involve both "objects" (evidentiary "facts" ranging from words allegedly heard in a conversation to a "smoking gun") and their bindings, information that has been previously stored in memory and activated based on trial evidence. Whether these objects and their schematic bindings can be dissociated in jury research contexts as they were in our studies is a question for subsequent research.

In conclusion, in this research we extend the application of distinctiveness effects whereby schema-irrelevant items are better remembered that schema-relevant items, to include the idea that distinctiveness effects can act independently on elements of an event and the binding between elements, a prediction derived from the basic science of episodic memory. In terms of object-location binding, we show that enhanced memory for an object viewed in an unexpected location can occur in the face of relatively high levels of false memories for an expected object-location binding. We attribute these findings to active competition from evoked expected bindings leading to source memory errors. 


\section{Acknowledgements}

The authors wish to thank David Gaskell and Joshua Dickinson for the photography of the stimuli, Simon Slavin for development of the programs used in the studies, and Burcu Soy for conducting the inter-observer agreement coding. We also thank Padraic Monaghan for useful feedback on an earlier draft of this manuscript. 


\section{References}

Aizpurua, A., Garcia-Bajos, E., \& Migueles, M. (2009). False memories for a robbery in young and older adults. Applied Cognitive Psychology, 23, 174-187. doi: 10.1002/acp.1461

Aminoff, E., Schacter, D. L., \& Bar, M. (2008). The cortical underpinnings of context-based memory distortion. Journal of Cognitive Neuroscience, 20, $2226-2237$.

Bartlett, F. C. (1932). Remembering: A study in experimental and social psychology. Cambridge, UK: Cambridge University Press.

Batchelder, W. H. \& Riefer, D. M. (1990). Multinomial processing models of source monitoring. Psychological Review, 97, 548-564.

Bayen, U. J. \& Kuhlmann, B. G. (2011). Influences of source-item contingency and schematic knowledge on source monitoring: Tests of the probability-matching account. Journal of Memory and Language, 64, 1-17. doi:

10.1016/j.jml.2010.09.001

Bayen, U. J., Nakamura, G. V., Dupuis, S. E., \& Yang, C.-L. (2000). The use of schematic knowledge about sources in source monitoring. Memory \& Cognition, 28, 480-500.

Brewer, W. F. \& Treyens, J. C. (1981). Role of schemata in memory for places. Cognitive Psychology, 13, 207-230.

Bower, G. H., Black, J. B., \& Turner, T. J. (1979). Scripts in comprehension and memory. Cognitive Psychology, 11, 177-220.

Byrne, P., Becker, S., \& Burgess, N. (2007). Remembering the past and imagining the future: A neural model of spatial memory and imagery. Psychological Review, 114, 340 -375. doi:10.1037/0033- 295X.114.2.340 
Cook, G. I., Marsh, R. L., \& Hicks, J. L. (2003). Halo and devil effects demonstrate valenced-based influences on source-monitoring decisions. Consciousness and Cognition, 12, 257-278. doi: 10.1016/S1053-8100(02)00073-9

Friedman, A. (1979). Framing pictures: The role of knowledge in automatized encoding and memory for gist. Journal of Experimental Psychology: General, $108,316-355$

Gallo, D. A. (2010). False memories and fantastic beliefs: 15 years of the DRM illusion. Memory \& Cognition, 38, 833-848. doi: 10.3758/MC.38.7.833

Garcia-Bajos, E. \& Migueles, M. (2003). False memories for script actions in a mugging account. European Journal of Cognitive Psychology, 15, 195-208. doi: $10.1080 / 09541440244000102$

Graesser, A. C., Gordon, S. E., \& Sawyer, J. D. (1979).Recognition memory for typical and atypical actions in scripted activities: Tests of a script pointer + tag hypothesis. Journal of Verbal Learning and Verbal Behavior, 18, 319-332.

Graesser, A. C., Woll, S. B., Kowalski, D. J., \& Smith, D. A. (1980). Memory for typical and atypical actions in scripted activities. Journal of Experimental Psychology: Human Learning and Memory, 6, 503-515.

Hardt, O., Einarsson, E. Ö., \& Nader, K. (2010). A bridge over troubled water: Reconsolidation as a link between cognitive and neuroscientific memory research traditions. Annual Review of Psychology, 61, 141-67. doi: 10.1146/annurev.psych.093008.100455

Hess, T. M. \& Slaughter, S. J. (1990). Schematic knowledge influences on memory for scene information in young and older adults. Developmental Psychology, $26,855-865$. 
Hicks, J. L. \& Cockman, D. W. (2003). The effect of knowledge on source memory and decision processes. Journal of Memory and Language, 48, 489-501. doi: 10.1016/S0749-596X(02)00537-5

Hollingworth, A. (2009). Two forms of scene memory guide visual search: Memory for scene context and memory for the binding of target object to scene location. Visual Cognition, 17, 273-291. doi: 10.1080/1350680802193367

Horner, A. \& Burgess, N. (2013). The associative structure of memory for multielement events. Journal of Experimental Psychology: General, 142, 13701383. doi: $10.1037 / \mathrm{a} 0033626$

Horner, A. \& Burgess, N. (2014). Pattern completion in multielement event engrams. Current Biology, 24, 988-992. doi: 10.1016/j.cub.2014.03.012

Howe, M. L. \& Knott, L. (2015). The fallibility of memory in judicial processes: Lessons from the past and their modern consequences. Memory, 23, 633-656. doi: 10.1080/09658211.2015.1010709

Huntley, J., \& Costanzo, M. (2003). Sexual harassment stories: Testing a storymediated model of juror decision-making in civil litigation. Law \& Human Behavior, 27, 29-51.

Johnson, M. K., Hashtroudi, S., \& Lindsay, D. S. (1993). Source monitoring. Psychological Bulletin, 114, 3-28.

Kleider, H. M., Pezdek, K., Goldinger, S. D., \& Kirk, A. (2008). Schema-driven source misattribution errors: Remembering the expected from a witnessed event. Applied Cognitive Psychology, 22, 1-20. doi: 10.1002/acp.1361

Knierim, J. J., Lee, I., \& Hargreaves, E. L. (2006). Hippocampal place cells: Parallel input streams, subregional processing, and implications for episodic memory. Hippocampus, 16, 755-764. doi: 10.1002/hipo.20203 
Konopka, A. E. \& Benjamin, A. S. (2009). Schematic knowledge changes what judgments of learning predict in a source memory task. Memory \& Cognition, 37, 42-51. doi: 10.3758/MC.37.1.42

Kuhlmann, B., Vaterrodt, B \& Bayen, U. J. (2012). Schema bias in source monitoring varies with encoding conditions: Support for a probability-matching account. Journal of Experimental Psychology: Learning, Memory, and Cognition, 38, 1365-1376. doi: 10.1037/a0028147

Lampinen, J. M., Copeland, S. M., \& Neuschatz, J. S. (2001). Recollection of things schematic: Room schemas revisited. Journal of Experimental Psychology: Learning, Memory, and Cognition, 27, 1211-1222.

Lampinen, J. M., Faries, J. M., Neuschatz, J. S., \& Toglia, M. P. (2000). Recollections of things schematic: The influence of scripts on recollective experience. Applied Cognitive Psychology, 14, 543-554.

Lew, A. R. (2011). Looking beyond the boundaries: Time to put landmarks back on the cognitive map? Psychological Bulletin, 137, 484-507. doi: $10.1037 / \mathrm{a} 0022315$

Loftus, G. R. \& Mackworth, N. H. (1978). Cognitive determinants of fixation location during picture viewing. Journal of Experimental Psychology: Human Perception and Performance, 4, 565-572.

Mandler, J. M. \& Parker, R. E. (1976). Memory for descriptive and spatial information in complex pictures. Journal of Experimental Psychology: Human Learning and Memory, 2, 38-48.

McClelland, J. L., McNaughton, B. L., \& O'Reilly, R. C. (1995). Why are there complimentary learning systems in the hippocampus and neocortex: insights from the successes and failures of connectionist models of learning and 
memory. Psychological Review, 102, 419-457.

Mäntylä, T. \& Bächman, L., (1992). Aging and memory for expected and unexpected objects in real-world settings. Journal of Experimental Psychology: Learning, Memory, and Cognition, 18, 1298-1309.

Mather, M., Johnson, M. K., \& De Leonardis, D. (1999). Stereotype reliance in source monitoring: Age differences and neuropsychological test correlates. Cognitive Neuropsychology, 16, 437-458. doi: 10.1080/026432999380870

Migueles, M. \& García-Bajos, E. (1999). Recall, recognition, and confidence patterns in eyewitness testimony. Applied Cognitive Psychology, 13, 257-268.

Mitchell, K. J. \& Johnson, M. K. (2009). Source monitoring 15 years later: What have we learned from fMRI about the neural mechanisms of source memory? Psychological Bulletin, 135, 638-677. doi: 10.1037/a0015849

Nakamura, G. V. \& Graesser, A. C. (1985). Memory for script-typical and scriptatypical actions: A reaction time study. Bulletin of the Psychonomic Society, $23,384-386$.

Nakamura, G. V., Graesser, A. C., Zimmerman, J. A., \& Riha, J. (1985). Script processing in a natural situation. Memory \& Cognition, 13, 140-144.

Neuschatz, J. S., Lampinen, J. M., Preston, E. L., Hawkins, E. R. \& Toglia, M. P. (2002). The effect of memory schemata on memory and the phenomenological experience of natural situations. Applied Cognitive Psychology, 16, 687-708. doi: 10.1002/acp.824 
Pennington, N., \& Hastie, R. (1993). The story model for juror decision making. In R. Hastie (Ed.), Inside the juror: The psychology of juror decision making (pp. 192-221). New York: Cambridge University Press.

Pezdek, K., Whetstone, T., Reynolds, K., Askari, N., \& Dougherty, T. (1989). Memory for real-world scenes: The role of consistency with schema expectation. Journal of Experimental Psychology: Learning, Memory, and Cognition, 15, 587-595.

Postma, A., Kessels, R. P. C., \& van Asselen, M. (2008). How the brain remembers and forgets where things are: The neurocognition of object-location memory. Neuroscience and Biobehavioral Reviews, 32, 1339-1345. doi: 10.1016/j.neubiorev.2008.05.001

Preston, A. R. \& Eichenbaum, H. (2013). Interplay of hippocampus and prefrontal cortex in memory. $x$, R764-R773. doi: 10.1016/j.cub.2013.05.041

Roediger, H. L., Watson, J. M., McDermott, K. B., \& Gallo, D. A. (2001). Factors that determine false recall: A multiple regression analysis. Psychonomic Bulletin \& Review, 8, 385-407.

Rojahn, K. \& Pettigrew, T. F. (1992). Memory for schema-relevant information: A meta-analytic resolution. British Journal of Social Psychology, 31, 81-109.

Rolls, E. T. \& Treves, A. (1998). Neural networks and brain function. Oxford: Oxford University Press.

Schacter, D. L., Israel, L., \& Racine, C. (1999). Suppressing false recognition in younger and older adults: The distinctiveness heuristic. Journal of Memory and Language, 40, 1-24.

Schank, R. C. (1982). Dynamic theory: A theory of reminding and learning in computers and people. Cambridge, UK: Cambridge University Press. 
Schank, R. C. (1999). Dynamic memory revisited. Cambridge, UK: Cambridge University Press.

Sherman, J. W. \& Bessenoff, G. R. (1999). Stereotypes as source-monitoring cues: On the interaction between episodic and semantic memory. Psychological Science, 10, 106-110.

Slavin, S. (2003-2014). PsyScript (Version 3.2.1) [Computer software]. Lancaster University. Retrieved March 15, 2013. Available from http://www.psych.lancs.ac.uk/research/research-software

Stangor, C. \& McMillan, D. (1992). Memory for expectancy-congruent and expectancy-incongruent information: A review of the social and social developmental literatures. Psychological Bulletin, 111, 42-61.

Straube, B., Meyer, L., Green, A., \& Kircher, T. (2014). Semantic relation vs. surprise: The differential effects of related and unrelated co-verbal gestures on neural encoding and subsequent recognition. Brain Research, 1567, 42-56. doi: 10.1016/j.brainres.2014.04.012

Torralba, A., Oliva, A., Castelhano, M. S., Henderson, J. M. (2006). Contextual guidance of eye movements and attention in real-world scenes: The role of global features in object search. Psychological Review, 113, 766-786. doi: 10.1037/0033-295X.113.4.766

Tuckey, M. R. \& Brewer, N. (2003). The influence of schemas, stimulus ambiguity, and interview schedule on eyewitness memory over time. Journal of Experimental Psychology: Applied, 9, 101-118. doi: 10.1037/1076898X.9.2.101 
Van Kesteren, M. T. R., Ruiter, D. J., Fernández, G., \& Henson, R. N. (2012). How schema and novelty augment memory formation. Trends in Neurosciences, 35, 211-219. doi: 10.1016/j.tins.2012.02.001

Warren, D. E., Jones, S. H., Duff, M. C., \& Tranel, D. (2014). False recall is reduced by damage to the ventromedial prefrontal cortex: Implications for understanding the neural correlates of schematic memory. Journal of Neuroscience, 34, 7677-7682. doi: 10.1523/JNEUROSCI.0119-14.2014

Yamada, R. \& Itsukushima, Y. (2013). The schema provokes a disparity of false recollection between actions and objects in an everyday scene. Scandinavian Journal of Psychology, 54, 276-282. doi: 10.1111/sjop.12051

Yamada, R. \& Itsukushima, Y. (2013). The effects of schema on recognition memories and subjective experiences for actions and objects. Japanese Psychological Research, 55, 366-377. doi: 10.1111/jpr.12016 


\section{Table 1.}

Target objects and their locations within the room scenes used in studies $1,2 \& 3$. Note. The Ms and SDs of ratings for schema-relevance ( $1=$ very usual, $10=$ very unusual) for each object in the relevant normative study are provided in the left-hand column, and the mean ratings for location expectedness for each schema-relevant object are provided in the 3 rightmost columns. The numbers in bold square brackets represent the number of participants out of 12 that placed the schema-relevant object in the expected location used in studies 1 and 2 as a baseline preference in Study 3 (see text for further details).

\begin{tabular}{|c|c|c|c|}
\hline Objects & $\begin{array}{l}\text { Expected } \\
\text { Location }\end{array}$ & $\begin{array}{c}\text { Unexpected } \\
\text { Location List } 1 \\
\end{array}$ & $\begin{array}{c}\text { Unexpected } \\
\text { Location List } 2\end{array}$ \\
\hline \multicolumn{4}{|c|}{$\begin{array}{c}\text { Bathroom } \\
\end{array}$} \\
\hline $\begin{array}{l}\text { 1. Bath toy } \\
(3.4,2.0)\end{array}$ & $\begin{array}{l}\text { Back-left corner of } \\
\text { bath }[4] \\
(1.3, .6)\end{array}$ & $\begin{array}{l}\text { Toilet lid } \\
(7.7,2.7)\end{array}$ & $\begin{array}{l}\text { Sink } \\
(8.3,1.4)\end{array}$ \\
\hline $\begin{array}{l}\text { 2. Shampoo } \\
(1.2, .6)\end{array}$ & $\begin{array}{l}\text { Front-left corner of } \\
\text { bath }[\mathbf{0}] \\
(1.1, .3)\end{array}$ & $\begin{array}{l}\text { Top of clothes- } \\
\text { drier } \\
(8.4,1.5)\end{array}$ & $\begin{array}{l}\text { Floor next to sink } \\
(7.5,2.4)\end{array}$ \\
\hline $\begin{array}{l}\text { 3. Toilet Roll } \\
(1.1, .3)\end{array}$ & $\begin{array}{l}\text { Left end of cistern } \\
{[2]} \\
(1.2, .4)\end{array}$ & $\begin{array}{l}\text { On bath taps } \\
(8.3,2.1)\end{array}$ & $\begin{array}{l}\text { Sink, right side of } \\
\text { taps } \\
(6.7,2.7)\end{array}$ \\
\hline $\begin{array}{l}\text { 4. Mouthwash } \\
(1.5, .8)\end{array}$ & $\begin{array}{l}\text { Window-ledge } \\
\text { above sink }[4] \\
(1.3, .8)\end{array}$ & $\begin{array}{l}\text { Bathmat } \\
(9.3,1.2)\end{array}$ & $\begin{array}{l}\text { Toilet lid } \\
(9.1,1.7)\end{array}$ \\
\hline $\begin{array}{l}\text { 5. Scales } \\
(2.5, .6)\end{array}$ & $\begin{array}{l}\text { Floor between sink } \\
\text { and toilet }[9] \\
(1.5,1.0)\end{array}$ & $\begin{array}{l}\text { Sink behind taps } \\
(9.4, .8)\end{array}$ & $\begin{array}{l}\text { Back/middle of } \\
\text { bath } \\
(9.7, .6)\end{array}$ \\
\hline $\begin{array}{l}\text { 6. Toilet Brush } \\
(1.2, .4)\end{array}$ & $\begin{array}{l}\text { Floor on right of } \\
\text { toilet [7] } \\
(1.0,0)\end{array}$ & $\begin{array}{l}\text { Floor, side of } \\
\text { shower } \\
(7.3,2.6)\end{array}$ & $\begin{array}{l}\text { Floor, side of bath } \\
(8.3,1.7)\end{array}$ \\
\hline $\begin{array}{l}\text { 7. Clock } \\
(6.5,2.8)\end{array}$ & - & Bathmat (back) & Window-ledge \\
\hline $\begin{array}{l}\text { 8. Notebook } \\
(8.2,1.5)\end{array}$ & - & Bathmat (front) & Front side of bath \\
\hline $\begin{array}{l}\text { 9. Handbag } \\
(8.3,1.6)\end{array}$ & - & Front side of bath & $\begin{array}{l}\text { Floor in front of } \\
\text { bathmat }\end{array}$ \\
\hline $\begin{array}{l}\text { 10. Bikelight } \\
(8.8,2.4)\end{array}$ & - & $\begin{array}{l}\text { Left-front of } \\
\text { bathmat }\end{array}$ & $\begin{array}{l}\text { Right side of } \\
\text { window-ledge }\end{array}$ \\
\hline $\begin{array}{l}\text { 11. Yoga Block } \\
(6.1,3.2)\end{array}$ & - & $\begin{array}{l}\text { Top of clothes- } \\
\text { drier }\end{array}$ & $\begin{array}{l}\text { Floor under } \\
\text { clothes-drier }\end{array}$ \\
\hline $\begin{array}{l}\text { 12. Nutcracker } \\
(8.6,1.5)\end{array}$ & - & Front edge of bath & $\begin{array}{l}\text { Back wall (stuck } \\
\text { on) }\end{array}$ \\
\hline \multicolumn{4}{|c|}{ Kitchen } \\
\hline $\begin{array}{l}\text { 1. Microwave } \\
(1.2, .6) \\
\text { 2. Kitchen Roll } \\
(1.4,1.0)\end{array}$ & $\begin{array}{l}\text { Shelf [0] } \\
(2.2,1.7) \\
\text { Work-surface right } \\
\text { of sink [1] } \\
(1.0,0)\end{array}$ & $\begin{array}{l}\text { Floor, back } \\
(9.5,1.7) \\
\text { Floor, back right } \\
(9.5,1.0)\end{array}$ & $\begin{array}{l}\text { Table, near wall } \\
(5.3,2.7) \\
\text { Stove, front left } \\
(8.7,1.6)\end{array}$ \\
\hline
\end{tabular}




\begin{tabular}{|c|c|c|c|}
\hline 3. Metal pan & Stove, front left [6] & $\begin{array}{l}\text { Stool } \\
(92-10)\end{array}$ & Floor near stool \\
\hline $\begin{array}{l}\text { 4. Toaster } \\
(1.0,0)\end{array}$ & $\begin{array}{l}\text { Work surface right } \\
\text { of sink [4] } \\
(1.1, .3)\end{array}$ & $\begin{array}{l}\text { Hook on wall } \\
\text { above calendar } \\
(9.9, .3)\end{array}$ & $\begin{array}{l}\text { Floor near stove } \\
(9.3,1.1)\end{array}$ \\
\hline $\begin{array}{l}\text { 5. Fruitbowl } \\
(1.9,1.2)\end{array}$ & $\begin{array}{l}\text { Table }[11] \\
(1.1, .3)\end{array}$ & $\begin{array}{l}\text { Sink } \\
(6.6,2.7)\end{array}$ & $\begin{array}{l}\text { Foot-shelf of table } \\
(6.3,2.7)\end{array}$ \\
\hline $\begin{array}{l}\text { 6. Green teapot } \\
(1.8,1.1)\end{array}$ & $\begin{array}{l}\text { Work surface right } \\
\text { of sink [2] } \\
(1.1, .3)\end{array}$ & $\begin{array}{l}\text { Foot-shelf of table } \\
(7.8,2.5)\end{array}$ & $\begin{array}{l}\text { Stool } \\
(8.8,1.3)\end{array}$ \\
\hline $\begin{array}{l}\text { 7. Walking boots } \\
(7.9,1.8)\end{array}$ & - & $\begin{array}{l}\text { Middle-right of } \\
\text { floor }\end{array}$ & $\begin{array}{l}\text { Work-surface left } \\
\text { of sink }\end{array}$ \\
\hline $\begin{array}{l}\text { 8. Bathtowel } \\
(8.4,2.5)\end{array}$ & - & Rail of table & Back of stool \\
\hline $\begin{array}{l}\text { 9. Toy } \\
(8.5,1.6)\end{array}$ & - & $\begin{array}{l}\text { Worksurface to left } \\
\text { of stove }\end{array}$ & Window-ledge \\
\hline $\begin{array}{l}\text { 10. Pile of books } \\
(6.2,2.4)\end{array}$ & - & Floor near stool & Window-ledge \\
\hline $\begin{array}{l}\text { 11. Umbrella } \\
(7.7,1.6)\end{array}$ & - & $\begin{array}{l}\text { Back of Stool near } \\
\text { wall }\end{array}$ & Floor behind table \\
\hline $\begin{array}{l}\text { 12. Hat } \\
(8.2,1.2)\end{array}$ & - & Table & $\begin{array}{l}\text { Pinboard next to } \\
\text { windowledge }\end{array}$ \\
\hline \multicolumn{4}{|c|}{ Living Room } \\
\hline $\begin{array}{l}1 . \mathrm{TV} \\
(1.5,1.2)\end{array}$ & $\begin{array}{l}\text { Shelf [10] } \\
(1.4, .9)\end{array}$ & $\begin{array}{l}\text { Floor near shelves } \\
(7.5,2.4)\end{array}$ & $\begin{array}{l}\text { Sofa } \\
(9.3,1.1)\end{array}$ \\
\hline $\begin{array}{l}\text { 2. Painting of } \\
\text { beach } \\
(1.6, .8)\end{array}$ & $\begin{array}{l}\text { Wall above } \\
\text { mantelpiece [10] } \\
(1.1, .3)\end{array}$ & $\begin{array}{l}\text { Hearth } \\
(7.6,2.7)\end{array}$ & $\begin{array}{l}\text { French window } \\
(8.2,2.9)\end{array}$ \\
\hline $\begin{array}{l}\text { 3. Paper lamp } \\
(2.3,1.1)\end{array}$ & $\begin{array}{l}\text { Sidetable near } \\
\text { shelves [0] } \\
(3.3,2.5)\end{array}$ & $\begin{array}{l}\text { Mantelpiece } \\
(3.3,2.5)\end{array}$ & $\begin{array}{l}\text { Floor near French } \\
\text { window } \\
(5.2,3.1)\end{array}$ \\
\hline $\begin{array}{l}\text { 4. Hi-Fi } \\
(2.7,1.1)\end{array}$ & $\begin{array}{l}\text { Shelf [0] } \\
(1.3, .5)\end{array}$ & $\begin{array}{l}\text { Near French } \\
\text { window } \\
(6.6,2.6)\end{array}$ & $\begin{array}{l}\text { Log-basket } \\
(9.6, .8)\end{array}$ \\
\hline $\begin{array}{l}\text { 5. Photos in frame } \\
(1.7,1.1)\end{array}$ & $\begin{array}{l}\text { Shelf [1] } \\
(1.1, .3)\end{array}$ & $\begin{array}{l}\text { Floor near rocking } \\
\text { chair } \\
(9.4, .8)\end{array}$ & $\begin{array}{l}\text { Hearth } \\
(7.0,3.0)\end{array}$ \\
\hline $\begin{array}{l}\text { 6. Vase with } \\
\text { flowers } \\
(2.2,1.0)\end{array}$ & $\begin{array}{l}\text { Sidetable near sofa } \\
{[0]} \\
(1.3, .5)\end{array}$ & $\begin{array}{l}\text { Sofa } \\
(9.1,1.1)\end{array}$ & $\begin{array}{l}\text { Rocking chair } \\
(9.1,1.5)\end{array}$ \\
\hline $\begin{array}{l}\text { 7. Doll } \\
(4.2,1.2)\end{array}$ & - & Shelf & $\begin{array}{l}\text { Lower shelf of } \\
\text { sidetable near sofa }\end{array}$ \\
\hline $\begin{array}{l}\text { 8. Stripey bed } \\
\text { pillow } \\
(4.1,2.2)\end{array}$ & - & $\begin{array}{l}\text { Back of rocking } \\
\text { chair }\end{array}$ & $\begin{array}{l}\text { Lower shelf of } \\
\text { sidetable near sofa }\end{array}$ \\
\hline $\begin{array}{l}\text { 9. Sandals } \\
(6.3,2.4)\end{array}$ & - & Floor near hearth & Shelf \\
\hline $\begin{array}{l}\text { 10. Trowel } \\
(9.2,1.5)\end{array}$ & - & Floor near hearth & Hearth \\
\hline 11. Gold rubber & & Mantelpiece & Floor near rocking \\
\hline
\end{tabular}


duck

$(8.6,2.1)$

12. Blue cardboard castle

$(6.5,1.8)$ chair

Top shelf

Floor near sofa

\begin{tabular}{|c|c|c|c|}
\hline \multicolumn{4}{|c|}{ Office } \\
\hline $\begin{array}{l}\text { 1. Bin } \\
(1.3, .6)\end{array}$ & $\begin{array}{l}\text { Floor near desk [5] } \\
(1.6,1.5)\end{array}$ & $\begin{array}{l}\text { Near end of desk } \\
(7.8,1.9)\end{array}$ & $\begin{array}{l}\text { Top of filing } \\
\text { cabinet } \\
(8.3,2.1)\end{array}$ \\
\hline $\begin{array}{l}\text { 2. Lap-top } \\
(1.2, .4)\end{array}$ & $\begin{array}{l}\text { Far end of desk [0] } \\
(1.3, .6)\end{array}$ & $\begin{array}{l}\text { Floor, near middle } \\
\text { end of desk } \\
(9.1,1.8)\end{array}$ & $\begin{array}{l}\text { Top of boxes near } \\
\text { filing cabinet } \\
(7.8,2.1)\end{array}$ \\
\hline $\begin{array}{l}\text { 3. Lamp } \\
(1.4, .8)\end{array}$ & $\begin{array}{l}\text { Far end of desk [0] } \\
(1.1, .3)\end{array}$ & $\begin{array}{l}\text { On chair round the } \\
\text { table } \\
(9.4, .7)\end{array}$ & $\begin{array}{l}\text { Under chair round } \\
\text { the table } \\
(9.6, .5)\end{array}$ \\
\hline $\begin{array}{l}\text { 4. Printer } \\
(1.4, .9)\end{array}$ & $\begin{array}{l}\text { Middle end, desk } \\
{[3]} \\
(1.0,0)\end{array}$ & $\begin{array}{l}\text { Table } \\
(5.5,2.5)\end{array}$ & $\begin{array}{l}\text { Chair round table } \\
(9.2,1.0)\end{array}$ \\
\hline $\begin{array}{l}\text { 5. Desk-Chair } \\
(1.0,1.0)\end{array}$ & $\begin{array}{l}\text { Next to far end of } \\
\text { desk }[0] \\
(1.5, .9)\end{array}$ & $\begin{array}{l}\text { At table } \\
(4.8,2.6)\end{array}$ & $\begin{array}{l}\text { Middle of floor } \\
(5.8,2.8)\end{array}$ \\
\hline $\begin{array}{l}\text { 6. 'Phone } \\
(1.2, .4)\end{array}$ & $\begin{array}{l}\text { Middle end, desk } \\
{[8]} \\
(1.0,0)\end{array}$ & $\begin{array}{l}\text { On chair } \\
(9.3, .8)\end{array}$ & $\begin{array}{l}\text { Under chair } \\
(9.7, .7)\end{array}$ \\
\hline $\begin{array}{l}\text { 7. Carafe } \\
(7.6,2.2)\end{array}$ & - & $\begin{array}{l}\text { Top of filing } \\
\text { cabinet }\end{array}$ & Table \\
\hline $\begin{array}{l}\text { 8. Yogamat } \\
(7.3,2.6)\end{array}$ & - & Floor & Chair \\
\hline $\begin{array}{l}\text { 9. Climbing shoes } \\
(6.3,2.0)\end{array}$ & - & Near end of desk & Floor \\
\hline $\begin{array}{l}\text { 10. Green cushion } \\
(6.0,1.8)\end{array}$ & - & $\begin{array}{l}\text { Floor near filing } \\
\text { cabinet }\end{array}$ & Far end of desk \\
\hline $\begin{array}{l}\text { 11. Police Helmet } \\
(9.3,1.5)\end{array}$ & - & Near end of desk & Table \\
\hline $\begin{array}{l}\text { 12. Red Kettle } \\
(3.2,1.3)\end{array}$ & - & Floor, foreground & Table \\
\hline
\end{tabular}



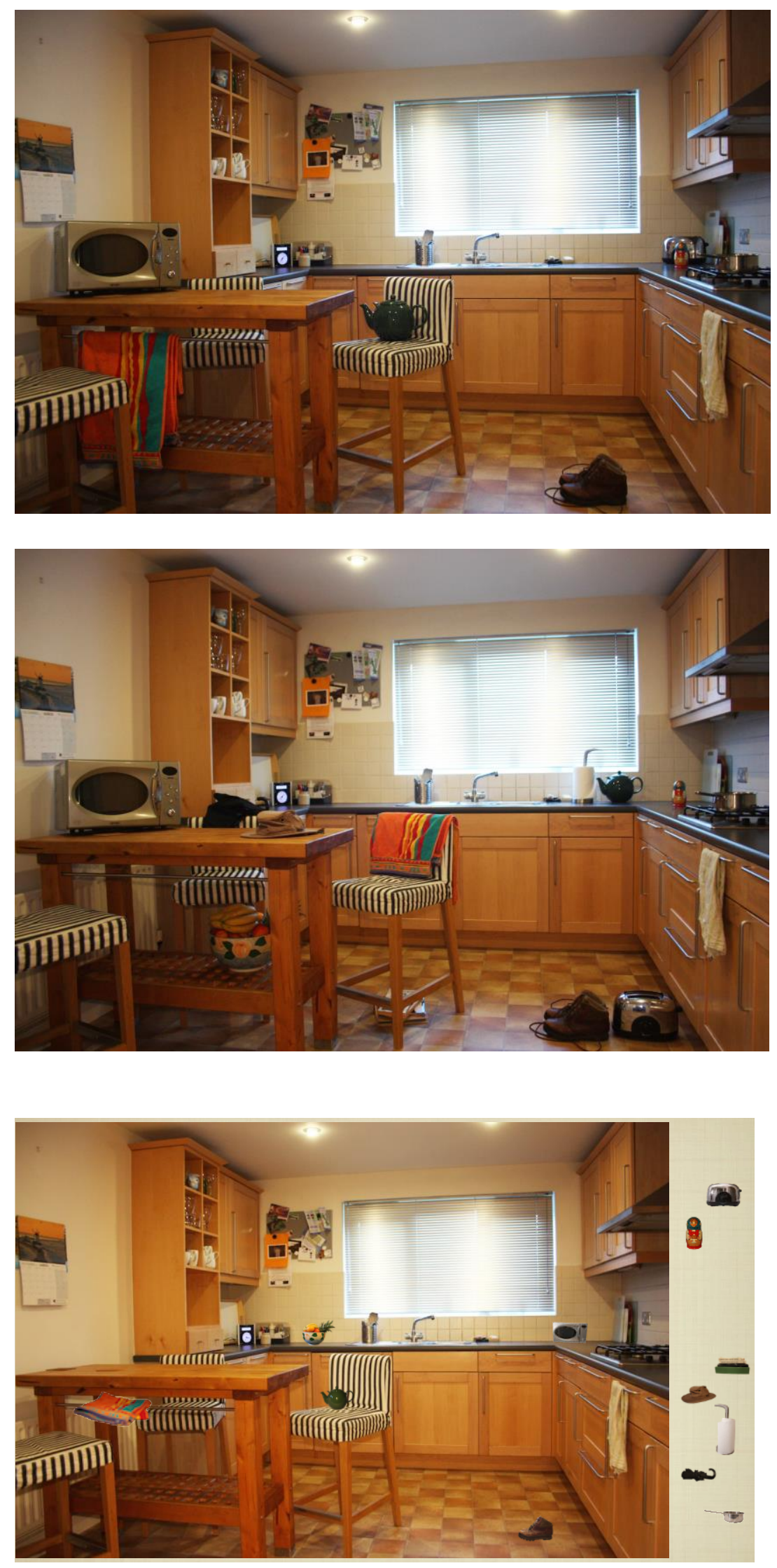

Figure 1. Top panel: Version 2 of the kitchen scene (see Figure S1) using objects 7.9. as schema-irrelevant objects, and using list 2 unexpected locations. Middle panel: One of the possible test images (out of 2) associated with the study image depicted in 
the top panel used in Study 1 (shift-to-expected condition). Bottom panel: Example of a participant's responses, having originally studied the image in the top panel, in the recall task of Study 2. Note. Schema-relevant objects in expected places at study are the pan and toaster, those in unexpected places are microwave and teapot, and those not present are fruitbowl and kitchen roll. 


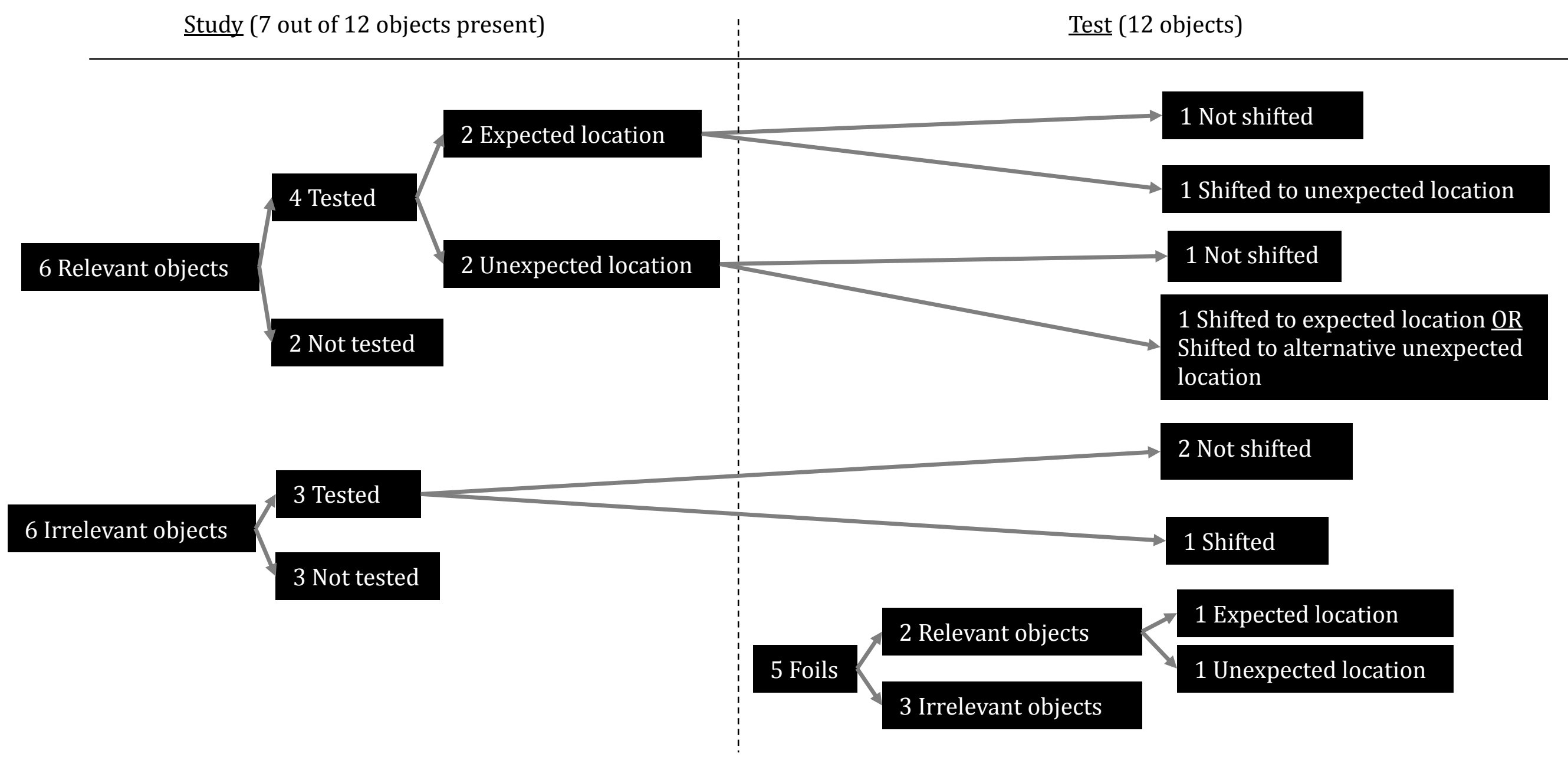

Figure 2. Numbers of different types of target objects and foils used for the study phase, and in the associated recognition test photograph in Study 1 . This scheme was the same for each of the 4 scenes, bathroom, kitchen, living room and office, utilized in Study 1. 



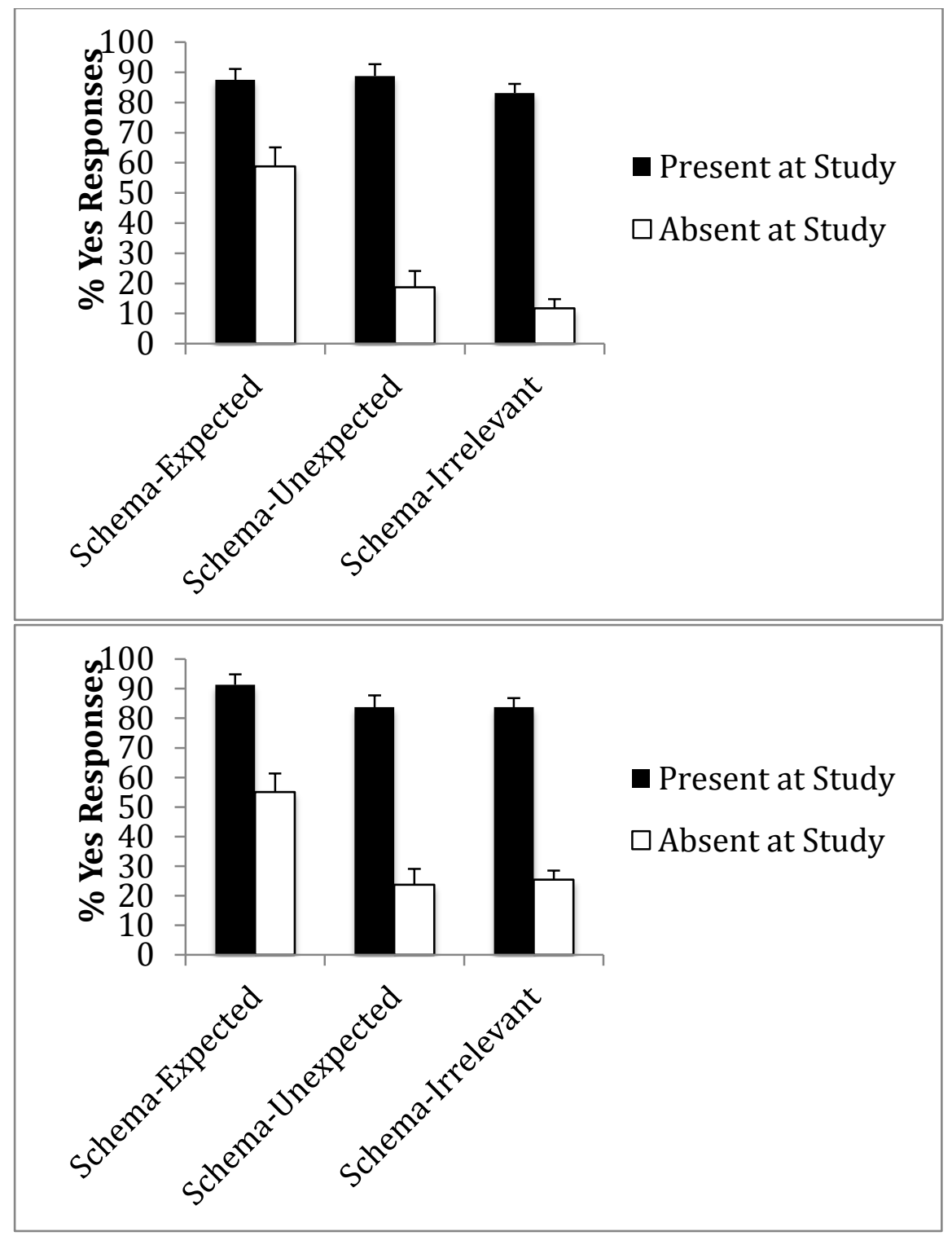

Figure 3. Mean percentage of Yes responses (and SEs) for schema-relevant objects at expected and unexpected locations, as well as schema-irrelevant objects, both present and absent during original study, in Study 1 (the Shift-to-Expected condition above, and the Shift-to-Unexpected condition below). Note. Responding Yes is correct for target objects that were present at study, and incorrect for foils that were not present. 


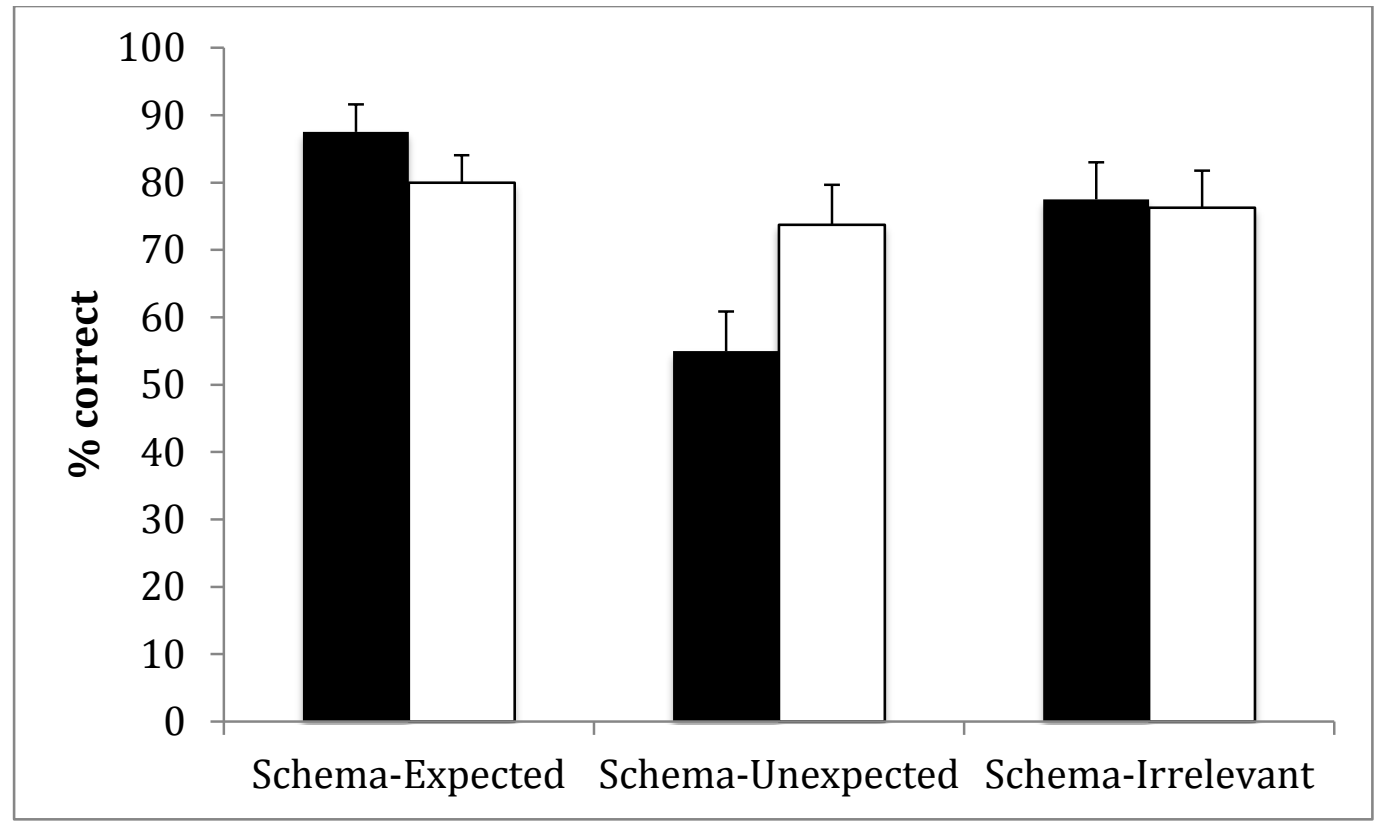

Figure 4. Mean percentage (and SEs) of correct responses (i.e. a "no" response to the question "was this object in this place before") as a function of whether objects were originally in schema-expected locations (shifted to unexpected locations in test photographs), schema-unexpected locations (shifted either to expected locations or different unexpected locations depending on condition), or were schema-irrelevant (shifted from one location to a different location), in Study 1. Black bars represent the "Shift-to-Expected" condition, and white bars the "Shift-to-Unexpected" condition. 


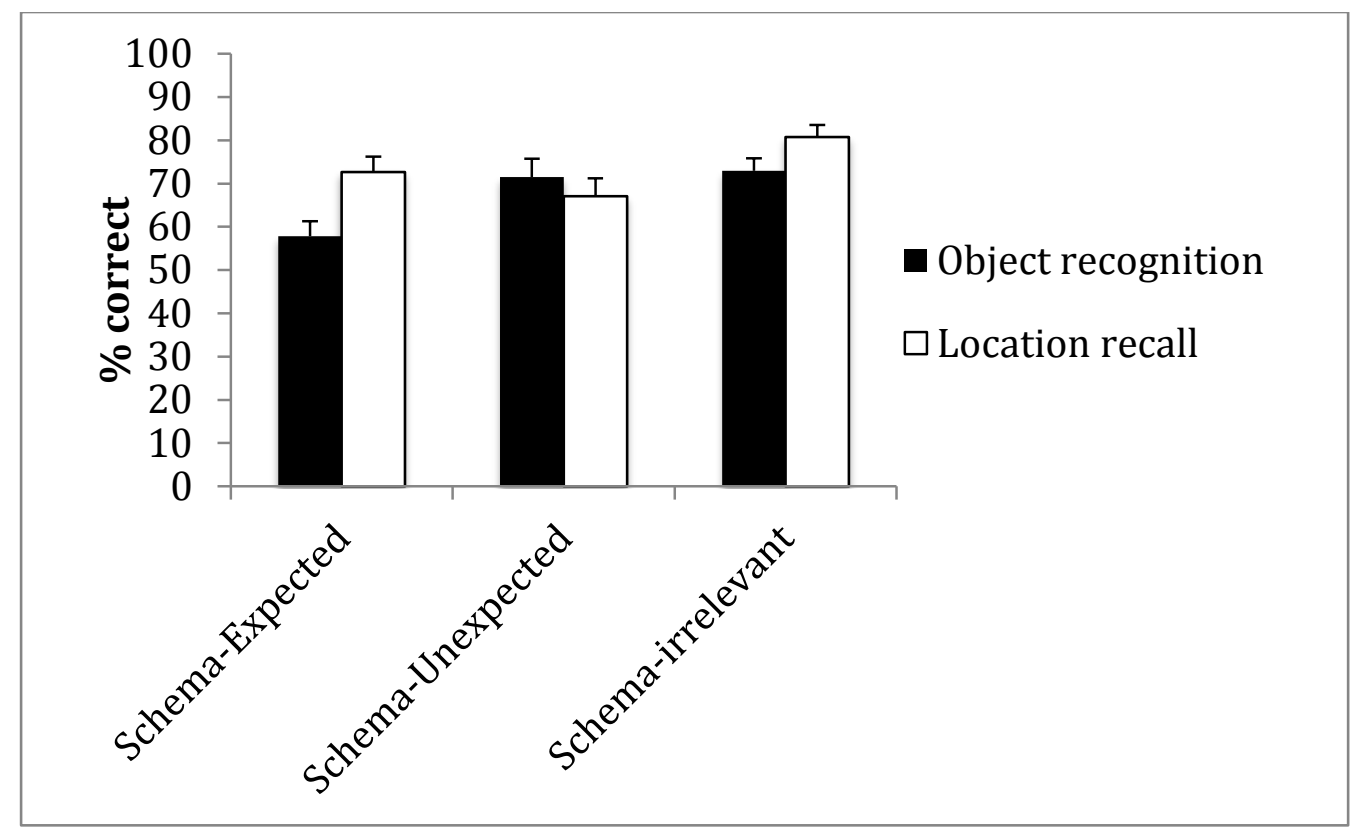

Figure 5. Mean percentage (and SEs) of correct object recognition (black bars) and mean percentage of correct placement (white bars) as a function of whether the schema-relevant objects were studied at expected and unexpected locations, and whether the object was schema-irrelevant, in Study 2. 

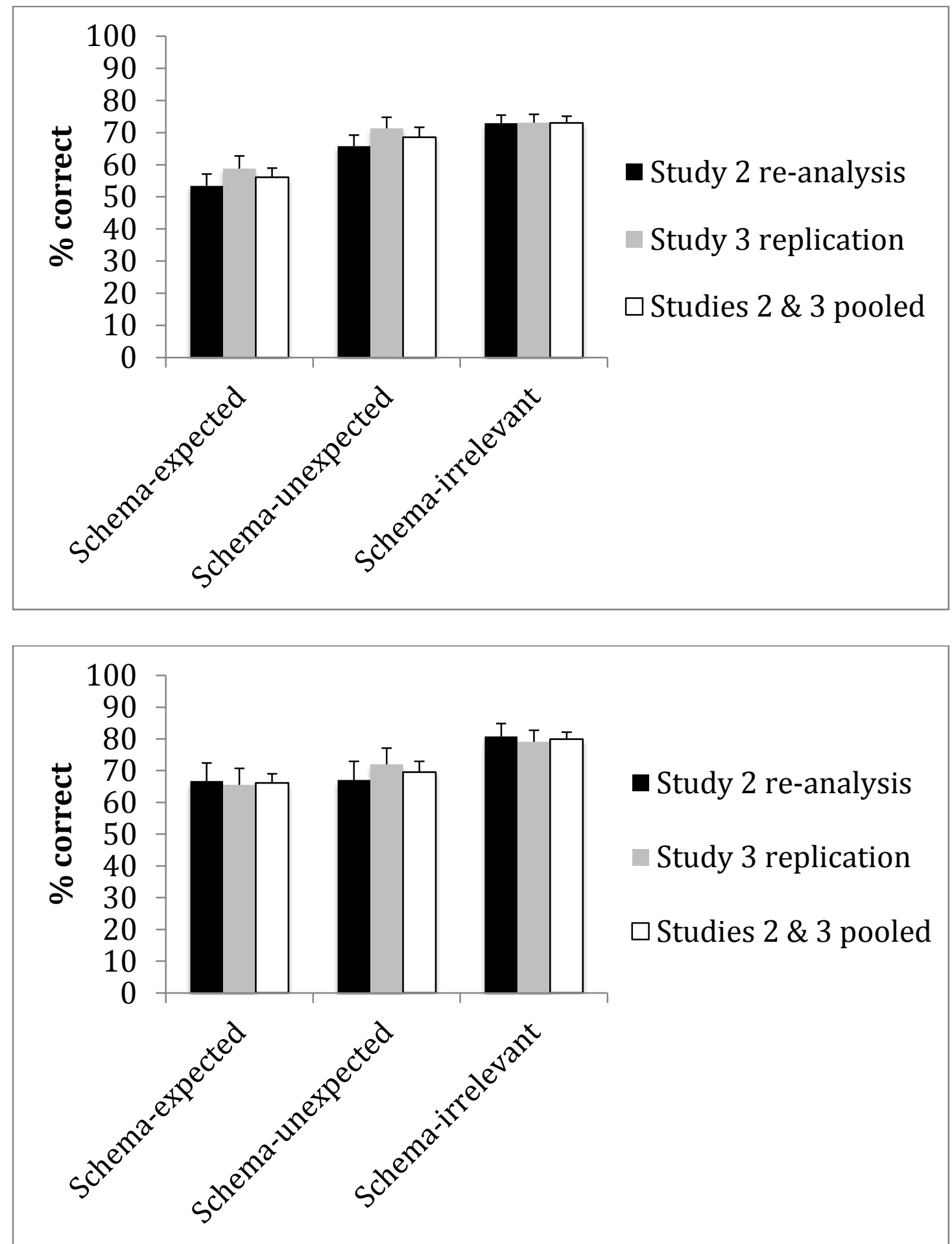

Figure 6. Mean percentage (and SEs) of correct object recognition (above) and mean percentage of correct placement (below) as a function of whether the schema-relevant objects were studied at expected and unexpected locations, and whether the object was schema-irrelevant, in the reanalysis of Study 2, the replication of Study 3 and the pooled data. Note that $N=31$ in the Study 2 reanalysis for location recall proportion, as one participant did not recognise any schema-relevant objects viewed in unexpected locations correctly across the 4 room scenes. 


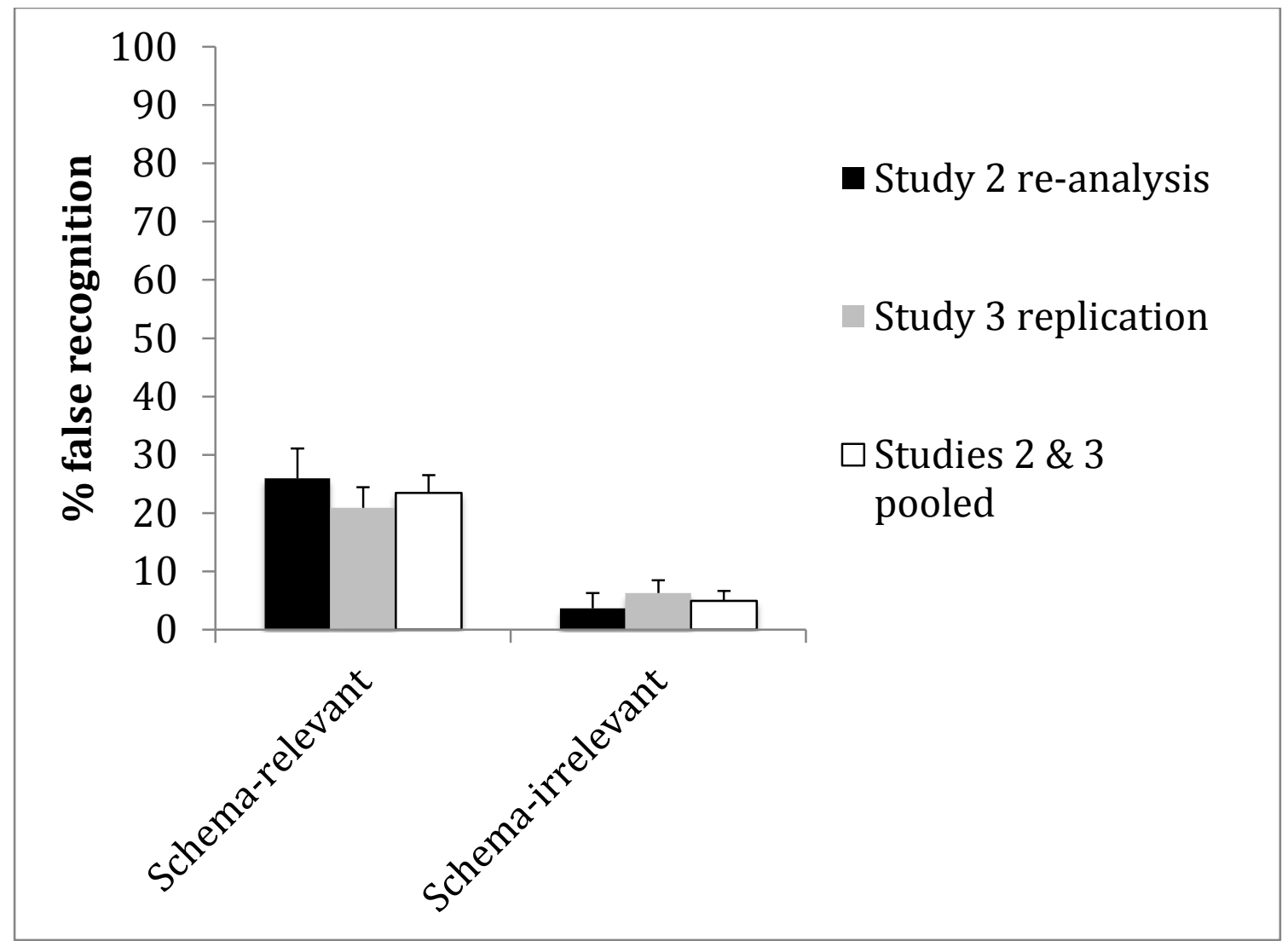

Figure 7. Mean percentage (and $S E$ s) of falsely recognised foil objects as a function of whether they were schema-relevant or irrelevant, in the re-analysis of Study 2, the replication of Study 3, and the pooled data. 
Table S1.

Placement errors for correctly recognised schema-relevant objects that were in expected locations (objects in italics are those excluded from Study 3 analyses).

\begin{tabular}{|c|c|c|c|}
\hline \multirow[t]{2}{*}{ Object } & \multirow[t]{2}{*}{ Placement } & \multicolumn{2}{|c|}{$\begin{array}{c}\text { Number of } \\
\text { occurrences }\end{array}$} \\
\hline & & Study 2 & Study 3 \\
\hline \multicolumn{4}{|c|}{ Errors to schema-consistent locations } \\
\hline Bath toy & Back and middle of bath & 0 & 1 \\
\hline Shampoo & $\begin{array}{l}\text { Back left corner of bath (three Study } \\
3 \text { substitutions for bath toy which } \\
\text { was unrecognised) }\end{array}$ & 2 & 3 \\
\hline Shampoo & Front middle of bath & 0 & 1 \\
\hline Shampoo & Back right corner of bath & 0 & 1 \\
\hline Shampoo & Sink* & 0 & 1 \\
\hline Toilet Roll & Right side of flush on cistern & 2 & 2 \\
\hline Toilet Roll & Right side of toilet on wooden casing & 1 & 1 \\
\hline Mouthwash & Right side of tap on sink & 2 & 0 \\
\hline Mouthwash & $\begin{array}{l}\text { Extreme left corner of sink-shelf } \\
\text { instead of middle }\end{array}$ & 0 & 1 \\
\hline Scales & Floor near shower & 1 & 0 \\
\hline Toilet brush & Floor on left side of toilet & 1 & 0 \\
\hline Microwave & Work-surface to left of sink & 0 & 1 \\
\hline Microwave & Work-surface to right of sink & 0 & 2 \\
\hline Kitchen Roll & Work-surface to right of stove & 1 & 0 \\
\hline Kitchen roll & On table & 0 & 1 \\
\hline Kitchen roll & Work surface to left of sink & 0 & 1 \\
\hline Pan & Front right ring on stove & 1 & 0 \\
\hline Pan & Back left ring on stove & 0 & 1 \\
\hline Toaster & Work-surface to left of sink & 3 & 0 \\
\hline Fruitbowl & Shelf & 0 & 2 \\
\hline Teapot & Work-surface to left of sink & 1 & 0 \\
\hline Teapot & Work-surface to left of stove & 1 & 0 \\
\hline Teapot & $\begin{array}{l}\text { On table (one instance where teapot } \\
\text { in location occupied by fruitbowl; } \\
\text { fruitbowl placed on shelf) }\end{array}$ & 0 & 2 \\
\hline $\mathrm{Hi}-\mathrm{Fi}$ & Shelf below that in study image & 1 & 3 \\
\hline $\mathrm{Hi}-\mathrm{Fi}$ & $\begin{array}{l}\text { Shelf below and right of that in study } \\
\text { image }\end{array}$ & 0 & 1 \\
\hline Photos in frame** & Wall above mantelpiece & 3 & 0 \\
\hline Photos in frame & Mantelpiece & 0 & 1 \\
\hline Vase with flowers & Mantelpiece & 1 & 1 \\
\hline Bin & Floor in front of filing cabinets & 1 & \\
\hline Lap-top & Near end of desk & 2 & 1 \\
\hline Lap-top & Middle part of desk & 0 & 2 \\
\hline Desk-lamp & $\begin{array}{l}\text { Middle part of desk (Study } 2 \text { error } \\
\text { where printer was although printer } \\
\text { unrecognised) }\end{array}$ & 1 & 1 \\
\hline Printer & Back segment of desk & 2 & 2 \\
\hline
\end{tabular}




\begin{tabular}{|c|c|c|c|}
\hline Printer & Front segment of desk & 1 & 1 \\
\hline Printer & Shelving & 0 & 1 \\
\hline Desk chair & Next to front segment of desk & 0 & 1 \\
\hline 'Phone & $\begin{array}{l}\text { Front segment of desk (where } \\
\text { climbing shoes were, climbing shoes } \\
\text { placed under desk) }\end{array}$ & 0 & 1 \\
\hline 'Phone & Back segment of desk & 0 & 4 \\
\hline \multicolumn{4}{|c|}{ Errors to non-schema-consistent locations } \\
\hline Toilet Roll & Right side of tap on sink & 1 & 0 \\
\hline Scales & $\begin{array}{l}\text { Bathmat (Study } 3 \text { error where } \\
\text { notebook was; notebook not } \\
\text { recognised) }\end{array}$ & 2 & 1 \\
\hline Paper lamp & Floor & 3 & 4 \\
\hline $\mathrm{Hi}-\mathrm{Fi}$ & Mantelpiece & 0 & 1 \\
\hline Lap-top & On top of filing cabinets & 1 & 0 \\
\hline Printer & Floor & 1 & 0 \\
\hline
\end{tabular}


Table $S 2$

Placement errors for correctly recognised schema-relevant objects that were in unexpected locations (objects in italics are those excluded from Study 3 analyses).

\begin{tabular}{|c|c|c|c|}
\hline Object & Placement & \multicolumn{2}{|c|}{$\begin{array}{c}\text { Number of } \\
\text { occurrences }\end{array}$} \\
\hline \multicolumn{2}{|c|}{ Errors to schema-consistent locations } & Study 2 & Study 3 \\
\hline Shampoo & Front right corner of bath & 2 & 0 \\
\hline Shampoo & Sink & 1 & 0 \\
\hline Shampoo & $\begin{array}{l}\text { Front centre of bath (where } \\
\text { nutcracker was, but nutcracker not } \\
\text { recognised) }\end{array}$ & 1 & 0 \\
\hline Toilet Roll & Left side of flush on cistern & 1 & 0 \\
\hline Toilet Roll & Right side of toilet on wooden casing & 1 & 1 \\
\hline Toilet Roll & Right side of flush on cistern & 1 & 0 \\
\hline Mouthwash & Window-ledge above sink & 1 & 0 \\
\hline Mouthwash & Sink & 2 & 0 \\
\hline Scales & Floor near shower & 1 & 0 \\
\hline Scales & Floor right side of toilet & 0 & 1 \\
\hline Toilet Brush & Right side of toilet & 2 & 4 \\
\hline Toilet Brush & Left side of toilet & 1 & 1 \\
\hline Microwave & $\begin{array}{l}\text { Work-surface to the right of sink } \\
\text { (where toaster was, but toaster not } \\
\text { recognised) }\end{array}$ & 2 & 0 \\
\hline Microwave & $\begin{array}{l}\text { Work-surface to the right of sink } \\
\text { (where toaster was; toaster } \\
\text { recognised but placed on work- } \\
\text { surface to left of sink) }\end{array}$ & 1 & 0 \\
\hline Kitchen Roll & Work-surface to right of sink & 1 & 2 \\
\hline Kitchen Roll & Work-surface to right of stove & 1 & 1 \\
\hline Kitchen Roll & $\begin{array}{l}\text { Work-surface to left of stove (one } \\
\text { error a substitution for toy; toy not } \\
\text { recognised) }\end{array}$ & 0 & 4 \\
\hline Pan & Front left ring & 1 & 1 \\
\hline Pan & Work surface left of stove & 0 & 1 \\
\hline Toaster & $\begin{array}{l}\text { Shelf (where the expected location } \\
\text { for microwave is, but no microwave } \\
\text { present in study image) }\end{array}$ & 1 & 0 \\
\hline Toaster & $\begin{array}{l}\text { Work-surface to right of sink (placed } \\
\text { where teapot was; teapot recognised } \\
\text { but placed on work-surface to left of } \\
\text { stove) }\end{array}$ & 1 & 0 \\
\hline Toaster & Work-surface to right of sink & 1 & 0 \\
\hline Toaster & Work-surface to left of sink & 0 & 2 \\
\hline Toaster & Work-surface right of stove & 0 & 1 \\
\hline Fruitbowl & Work-surface to left of sink & 2 & 1 \\
\hline Fruitbowl & Work-surface to right of sink & 1 & 2 \\
\hline Fruitbowl & Table & 1 & 1 \\
\hline$T V$ & Shelf & 1 & 5 \\
\hline Painting & Wall & 8 & 1 \\
\hline
\end{tabular}




\begin{tabular}{|c|c|c|c|}
\hline $\mathrm{Hi}-\mathrm{Fi}$ & $\begin{array}{l}\text { Shelf (one Study } 3 \text { error a } \\
\text { substitution for 'photos; 'photos not } \\
\text { recognised) }\end{array}$ & 5 & 1 \\
\hline Photos in frame & Mantelpiece & 1 & 2 \\
\hline Photos in frame & Wall (where painting was) & 1 & 0 \\
\hline Photos in frame & Shelf & 0 & 1 \\
\hline Vase with flowers & Bamboo side-table & 1 & 1 \\
\hline Vase with flowers & Mantelpiece & 0 & 3 \\
\hline Bin & Floor to right of filing cabinet & 1 & 1 \\
\hline Bin & Floor near front segment of desk & 0 & 1 \\
\hline Lap-top & Front section of desk & 1 & 1 \\
\hline Desk-lamp & Front section of desk & 1 & 0 \\
\hline Desk-lamp & Back section of desk & 0 & 1 \\
\hline Printer & Far end of desk against wall & 1 & 0 \\
\hline Printer & $\begin{array}{l}\text { Near segment of desk (Study } 3 \\
\text { substitution for helmet; helmet } \\
\text { placed where computer was on floor) }\end{array}$ & 0 & 1 \\
\hline Desk-chair & Next to front segment of desk & 0 & 1 \\
\hline \multicolumn{4}{|c|}{ Errors to non-schema-consistent locations } \\
\hline Bath-toy & Floor & 1 & 1 \\
\hline Bath-toy & $\begin{array}{l}\text { Left side of flush on cistern (where } \\
\text { toilet roll was; toilet roll not } \\
\text { recognised) }\end{array}$ & 0 & 1 \\
\hline Toilet roll & $\begin{array}{l}\text { Sink (where bath-toy was but bath- } \\
\text { toy not recognised) }\end{array}$ & 1 & 0 \\
\hline Mouthwash & $\begin{array}{l}\text { Top of clothes-drier where shampoo } \\
\text { was (shampoo recognised but placed } \\
\text { on bath) }\end{array}$ & 1 & 0 \\
\hline Mouthwash & $\begin{array}{l}\text { Floor near sink where shampoo was } \\
\text { (shampoo recognised but placed on } \\
\text { bath where nutcracker was; } \\
\text { nutcracker not recognised) }\end{array}$ & 1 & 0 \\
\hline Mouthwash & $\begin{array}{l}\text { On bathmat (where notebook was; } \\
\text { notebook not recognised) }\end{array}$ & 0 & 1 \\
\hline Microwave & Front part of floor & 1 & 0 \\
\hline Microwave & $\begin{array}{l}\text { Front part of floor (where boots } \\
\text { were, boots recognised but placed } \\
\text { nearer stool) }\end{array}$ & 1 & 0 \\
\hline Kitchen roll & Floor, but too central & 0 & 1 \\
\hline Pan & $\begin{array}{l}\text { Floor, but too far away from leg of } \\
\text { stool }\end{array}$ & 1 & 1 \\
\hline Toaster & $\begin{array}{l}\text { On floor, but too far back towards } \\
\text { sink }\end{array}$ & 0 & 1 \\
\hline$T V$ & $\begin{array}{l}\text { Floor under rocking chair instead of } \\
\text { floor near shelves }\end{array}$ & 1 & 0 \\
\hline $\mathrm{Hi}-\mathrm{Fi}$ & $\begin{array}{l}\text { Hearth (where painting was; painting } \\
\text { recognised but placed on wall) }\end{array}$ & 1 & 0 \\
\hline Bin & $\begin{array}{l}\text { Middle section of desk (bin on filing } \\
\text { cabinet in study image) }\end{array}$ & 1 & 0 \\
\hline Lamp & On filing cabinet (where carafe was) & 0 & 1 \\
\hline
\end{tabular}




\begin{tabular}{llll}
\hline Printer & On filing cabinet & 0 & 1 \\
'Phone & Table & 1 & 0 \\
'Phone & Floor & 0 & 1 \\
\hline
\end{tabular}


Table S3

Placement errors for correctly recognised schema-irrelevant objects

\begin{tabular}{|c|c|c|c|}
\hline \multirow[t]{3}{*}{ Object } & \multirow[t]{2}{*}{ Placement } & \multicolumn{2}{|c|}{$\begin{array}{c}\text { Number of } \\
\text { occurrences }\end{array}$} \\
\hline & & Study 2 & Study 3 \\
\hline & Bathroom & & \\
\hline Clock & Floor in front of bathmat & 1 & 0 \\
\hline Clock & $\begin{array}{l}\text { To right of notebook rather than } \\
\text { behind notebook on mat }\end{array}$ & 0 & 1 \\
\hline Clock & $\begin{array}{l}\text { Front right mat (where diary was; } \\
\text { diary not recognised) }\end{array}$ & 0 & 1 \\
\hline Notebook & $\begin{array}{l}\text { Left of clock on mat rather than in } \\
\text { front }\end{array}$ & 0 & 3 \\
\hline Notebook & Floor & 0 & 1 \\
\hline Notebook & Right of clock rather than in front & 0 & 1 \\
\hline Bikelight & Floor in front of bathmat & 1 & 1 \\
\hline Bikelight & Window-ledge & 0 & 1 \\
\hline Bikelight & Right front corner of bath & 0 & 1 \\
\hline Bikelight & Clothes drier in front of Yoga block & 0 & 1 \\
\hline Yoga block & Floor under clothes drier & 1 & 0 \\
\hline Yoga block & $\begin{array}{l}\text { Front middle of bath (where } \\
\text { nutcracker was; nutcracker not } \\
\text { recognised) }\end{array}$ & 1 & 0 \\
\hline Yoga block & Bath mat & 0 & 1 \\
\hline Nutcracker & $\begin{array}{l}\text { Bathmat (where bikelight was; } \\
\text { bikelight not recognised) }\end{array}$ & 1 & 0 \\
\hline & Kitchen & & \\
\hline Walking boots & Floor near leg of stool & 2 & 0 \\
\hline Walking boots & $\begin{array}{l}\text { Floor further back than in original } \\
\text { image }\end{array}$ & 3 & 2 \\
\hline Walking boots & On table shelf & 1 & 0 \\
\hline Bath towel & On short rather than long side of table & 0 & 1 \\
\hline Bath towel & On table & 0 & 1 \\
\hline Bath towel & Left of stove & 0 & 1 \\
\hline Toy & Work surface left of sink & 0 & 1 \\
\hline Pile of books & $\begin{array}{l}\text { On table (Study } 3 \text { error where hat was } \\
\text { on table; hat not recognised) }\end{array}$ & 1 & 1 \\
\hline Umbrella & Table shelf & 1 & 0 \\
\hline Umbrella & $\begin{array}{l}\text { On table (where fruitbowl was on } \\
\text { table; fruitbowl not recognised) }\end{array}$ & 1 & 0 \\
\hline Hat & $\begin{array}{l}\text { On table (where fruitbowl was on } \\
\text { table; fruitbowl not recognised) }\end{array}$ & 1 & 0 \\
\hline Hat & On base of stool & 1 & 0 \\
\hline Hat & $\begin{array}{c}\text { Back part of table instead of front } \\
\text { Living Room }\end{array}$ & 0 & 1 \\
\hline Doll & On adjacent shelf to left of correct one & 4 & 5 \\
\hline Doll & On shelf to left and below correct one & 0 & 3 \\
\hline Doll & On shelf below correct one & 0 & 2 \\
\hline Doll & On side table near hearth & 1 & 0 \\
\hline
\end{tabular}




\begin{tabular}{|c|c|c|c|}
\hline Stripey bed pillow & On base of rocking chair & 1 & 1 \\
\hline Stripey bed pillow & Floor & 0 & 1 \\
\hline Blue sandals & Towards middle of floor & 2 & 4 \\
\hline Blue sandals & Floor but towards log-basket & 3 & 2 \\
\hline Trowel & On side table near hearth & 1 & 0 \\
\hline Trowel & Too central on floor & 0 & 1 \\
\hline Gold rubber duck & Shelf & 0 & 1 \\
\hline Gold rubber duck & Floor (where trowel was) & 0 & 1 \\
\hline Blue castle & Lower shelf & 2 & 2 \\
\hline Blue castle & $\begin{array}{l}\text { Floor (where trowel was; trowel not } \\
\text { recognised) }\end{array}$ & 0 & 1 \\
\hline \multicolumn{4}{|c|}{ Office } \\
\hline Carafe & On boxes near filing cabinets & 0 & 1 \\
\hline Yoga mat & Near desk & 1 & 0 \\
\hline Yoga mat & Under chair nearest desk & 0 & 1 \\
\hline Climbing shoes & Floor below front part of desk & 5 & 2 \\
\hline Green cushion & $\begin{array}{l}\text { Floor near boxes on right of filing } \\
\text { cabinets }\end{array}$ & 1 & 0 \\
\hline Green cushion & $\begin{array}{l}\text { Front part of desk (where helmet was; } \\
\text { helmet not recognised) }\end{array}$ & 1 & 0 \\
\hline Green cushion & Adjacent to sofa & 0 & 1 \\
\hline Police helmet & $\begin{array}{l}\text { Floor (where computer was; computer } \\
\text { not recognised) }\end{array}$ & 0 & 1 \\
\hline Kettle & Floor too far left of chair & 2 & 0 \\
\hline Kettle & Floor too far right of chair & 2 & 1 \\
\hline Kettle & On far segment of desk & 2 & 0 \\
\hline Kettle & $\begin{array}{l}\text { On chair (where 'phone was; 'phone } \\
\text { recognised but placed on floor under } \\
\text { chair) }\end{array}$ & 0 & 1 \\
\hline
\end{tabular}




\begin{tabular}{|c|c|}
\hline \multicolumn{2}{|c|}{ Version 1} \\
\hline \multicolumn{2}{|c|}{$\begin{array}{l}\text { Schema-relevant objects in expected } \\
\text { places: } 1 . \& 2 .\end{array}$} \\
\hline \multicolumn{2}{|c|}{$\begin{array}{l}\text { Schema-relevant objects in unexpected } \\
\text { places: } 5 . \& 3 \text {. }\end{array}$} \\
\hline \multicolumn{2}{|c|}{$\begin{array}{l}\text { Schema-relevant objects not present: } 6 . \& \\
4 .\end{array}$} \\
\hline & \\
\hline Test 1 & Test 2 \\
\hline$\underline{\text { Shifted objects: }}$ & Shifted objects: \\
\hline $\begin{array}{l}2 \rightarrow \text { unexpected } \\
\text { location }\end{array}$ & $\begin{array}{l}1 \rightarrow \text { unexpected } \\
\text { location }\end{array}$ \\
\hline $\begin{array}{l}\text { 5. } \rightarrow \text { expected } \\
\text { (Condition 1) or } \\
\text { alternative } \\
\text { unexpected } \\
\text { (Condition 2) }\end{array}$ & $\begin{array}{l}\text { 3. } \rightarrow \text { expected } \\
\text { (Condition 1) or } \\
\text { alternative } \\
\text { unexpected } \\
\text { (Condition 2) }\end{array}$ \\
\hline $\begin{array}{l}\text { 7. or } \\
\text { 10. } \rightarrow \text { alternative } \\
\text { location }\end{array}$ & $\begin{array}{l}\text { 7. or } \\
\text { 10. } \rightarrow \text { alternative } \\
\text { location }\end{array}$ \\
\hline Added objects: & Added objects: \\
\hline $\begin{array}{l}\text { 6. to expected } \\
\text { location }\end{array}$ & $\begin{array}{l}\text { 4. to expected } \\
\text { location }\end{array}$ \\
\hline $\begin{array}{l}\text { 4. to unexpected } \\
\text { location }\end{array}$ & $\begin{array}{l}\text { 6. to unexpected } \\
\text { location }\end{array}$ \\
\hline
\end{tabular}

\section{Version 2 \\ Schema-relevant objects in expected places: 3 . \& 4 .}

Schema-relevant objects in unexpected places: $1 . \& 6$.

Schema-relevant objects not present: $2 . \&$ 5.

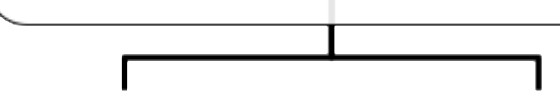

\begin{tabular}{|c|}
\hline \multirow[b]{2}{*}{ Shifted objects: } \\
\hline \\
\hline $\begin{array}{l}3 \rightarrow \text { unexpected } \\
\text { location }\end{array}$ \\
\hline $\begin{array}{l}1 \rightarrow \text { expected } \\
\text { (Condition 1) or } \\
\text { alternative } \\
\text { unexpected } \\
\text { (Condition 2) }\end{array}$ \\
\hline $\begin{array}{l}\text { 8. or } \\
11 . \rightarrow \text { alternative } \\
\text { location }\end{array}$ \\
\hline Added objects: \\
\hline $\begin{array}{l}\text { 2. to expected } \\
\text { location }\end{array}$ \\
\hline $\begin{array}{l}\text { 5. to unexpected } \\
\text { location }\end{array}$ \\
\hline
\end{tabular}

\section{Version 3}

Schema-relevant objects in expected places: 5. \& 6 .

Schema-relevant objects in unexpected places: $4 . \& 2$.

Schema-relevant objects not present: $3 . \&$ 1.

\begin{tabular}{|c|c|}
\hline Test 1 & Test 2 \\
\hline Shifted objects: & Shifted objects: \\
\hline $\begin{array}{l}5 \rightarrow \text { unexpected } \\
\text { location }\end{array}$ & $\begin{array}{l}6 \rightarrow \text { unexpected } \\
\text { location }\end{array}$ \\
\hline $\begin{array}{l}4 \rightarrow \text { expected } \\
\text { (Condition 1) or } \\
\text { alternative } \\
\text { unexpected } \\
\text { (Condition 2) }\end{array}$ & $\begin{array}{l}2 \rightarrow \text { expected } \\
\text { (Condition 1) or } \\
\text { alternative } \\
\text { unexpected } \\
\text { (Condition 2) }\end{array}$ \\
\hline $\begin{array}{l}\text { 9. or } \\
\text { 12. } \rightarrow \text { alternative } \\
\text { location }\end{array}$ & $\begin{array}{l}\text { 9. or } \\
\text { 12. } \rightarrow \text { alternative } \\
\text { location }\end{array}$ \\
\hline Added objects: & Added objects: \\
\hline $\begin{array}{l}\text { 3. to expected } \\
\text { location }\end{array}$ & $\begin{array}{l}\text { 1. to expected } \\
\text { location }\end{array}$ \\
\hline $\begin{array}{l}\text { 1. to unexpected } \\
\text { location }\end{array}$ & $\begin{array}{l}\text { 3. to unexpected } \\
\text { location }\end{array}$ \\
\hline
\end{tabular}


Figure S1. System utilised for counterbalancing which objects were used in the roles of schema-relevant objects in expected places, unexpected places, and not present at study. Which objects were shifted, and which schema-relevant foils were placed in expected and unexpected places, was also counterbalanced. The key to the object numbers for each of the 4 rooms used in studies 1-3 can be found in Table 1. Schema-irrelevant objects were also present in study photographs (either 7.-9. Or 10.-12. see Table 1), and schema-irrelevant foils (either 7.-9 or 10.-12., see Table 1) were also present in test photographs. 